University of Windsor

Scholarship at UWindsor

\title{
Movements of a deep-water fish: Establishing marine fisheries management boundaries in coastal Arctic waters
}

Nigel E. Hussey

University of Windsor

K. J. Hedges

A. N. Barkley

M. A. Treble

I. Peklova

See next page for additional authors

Follow this and additional works at: https://scholar.uwindsor.ca/biologypub

Part of the Biology Commons

\section{Recommended Citation}

Hussey, Nigel E.; Hedges, K. J.; Barkley, A. N.; Treble, M. A.; Peklova, I.; Webber, D. M.; Ferguson, S. H.;

Yurkowski, D. J.; Kessel, S. T.; Bedard, J. M.; and Fisk, A. T., "Movements of a deep-water fish: Establishing marine fisheries management boundaries in coastal Arctic waters" (2017). Ecological Applications, 27, 3, 687-704.

https://scholar.uwindsor.ca/biologypub/813

This Article is brought to you for free and open access by the Department of Biological Sciences at Scholarship at UWindsor. It has been accepted for inclusion in Biological Sciences Publications by an authorized administrator of Scholarship at UWindsor. For more information, please contact scholarship@uwindsor.ca. 


\section{Authors}

Nigel E. Hussey, K. J. Hedges, A. N. Barkley, M. A. Treble, I. Peklova, D. M. Webber, S. H. Ferguson, D. J. Yurkowski, S. T. Kessel, J. M. Bedard, and A. T. Fisk 


\title{
Movements of a deep-water fish: establishing marine fisheries management boundaries in coastal Arctic waters
}

\author{
Nigel E. Hussey, ${ }^{1,7}$ Kevin J. Hedges, ${ }^{2}$ Amanda N. Barkley, ${ }^{1}$ Margaret A. Treble, ${ }^{2}$ Iva Peklova, ${ }^{3}$ \\ Dale M. Webber, ${ }^{4}$ Steven H. Ferguson, ${ }^{2}$ David J. Yurkowski, ${ }^{5}$ Steven T. Kessel, ${ }^{5}$ \\ JeAnnette M. Bedard, ${ }^{6}$ And Aaron T. FisK ${ }^{5}$ \\ ${ }^{1}$ Biological Sciences, University of Windsor, 401 Sunset Avenue, Windsor, Ontario N9B3P4 Canada \\ ${ }^{2}$ Fisheries and Oceans Canada, Winnipeg, Manitoba R3T2N6 Canada \\ ${ }^{3}$ Za Zahradami 1407, 253 01, Hostivice, Czech Republic \\ ${ }^{4}$ Amirix Systems, 20 Angus Morton Drive, Bedford, Nova Scotia B4B0L9 Canada \\ ${ }^{5}$ Great Lakes Institute for Environmental Research, University of Windsor, Windsor, Ontario N9B3P4 Canada \\ ${ }^{6}$ School of Earth and Ocean Science, University of Victoria, Victoria, British Columbia V8P 5C2 Canada
}

\begin{abstract}
Management boundaries that define populations or stocks of fish form the basis of fisheries planning. In the Arctic, decreasing sea ice extent is driving increasing fisheries development, highlighting the need for ecological data to inform management. In Cumberland Sound, southwest Baffin Island, an indigenous community fishery was established in 1987 targeting Greenland halibut (Reinhardtius hippoglossoides) through the ice. Following its development, the Cumberland Sound Management Boundary (CSMB) was designated and a total allowable catch (TAC) assigned to the fishery. The CSMB was based on a sink population of Greenland halibut resident in the northern section of the Sound. Recent fishing activities south of the CSMB, however, raised concerns over fish residency, the effectiveness of the CSMB and the sustainability of the community-based winter fishery. Through acoustic telemetry monitoring at depths between 400 and $1200 \mathrm{~m}$, and environmental and fisheries data, this study examined the movement patterns of Greenland halibut relative to the CSMB, the biotic and abiotic factors driving fish movement and the dynamics of the winter fishery. Greenland halibut undertook clear seasonal movements between the southern and northern regions of the Sound driven by temperature, dissolved oxygen, and sea ice cover with most fish crossing the CSMB on an annual basis. Over the lifespan of the fishery, landfast ice cover initially declined and then became variable, limiting accessibility to favored fisher locations. Concomitantly, catch per unit effort declined, reflecting the effect of changing ice conditions on the location and effort of the fishery. Ultimately, these telemetry data revealed that fishers now target less productive sites outside of their favored areas and, with continued decreases in ice, the winter fishery might cease to exist. In addition, these novel telemetry data revealed that the CSMB is ineffective and led to its relocation to the entrance of the Sound in 2014. The community fishery can now develop an open-water fishery in addition to the winter fishery to exploit the TAC, which will ensure the longevity of the fishery under projected climate-change scenarios. Telemetry shows great promise as a tool for understanding deep-water species and for directly informing fisheries management of these ecosystems that are inherently complex to study.
\end{abstract}

Key words: acoustic telemetry; Canadian Arctic; catch per unit effort; declining ice cover; fisher location; fisheries planning; Reinhardtius hippoglossoides.

\section{INTRODUCTION}

For organisms that reside below the photic zone of oceans, daily, annual, and ontogenetic behavioral routines remain largely unknown. Fisheries catch data have historically provided insight on the spatiotemporal occurrence

Manuscript received 21 January 2016; revised 6 October 2016; accepted 21 October 2016. Corresponding Editor: Brice $\mathrm{X}$. Semmens.

${ }^{7}$ E-mail: nehussey@uwindsor.ca of animals, but single time-point data represent a simplified model of actual behaviors. Given recent revelations over the scales and complexities of fish movements in the epipelagic zone (Hussey et al. 2015), it is likely that deep-water organisms show similar behaviors, but with additional habitat-specific effects that drive lower metabolic rates, and limit visual cues with the majority of species assumed to be stenotopic (Wilson and Hessler 1987). With increasing demands on global marine resources, there is mounting pressure for innovative fisheries 
exploration. Habitats below the photic zone are viewed as lucrative and profitable environments to assist in addressing this resource need, but data for management of these potentially fragile ecosystems is lacking (Norse et al. 2012).

To date, establishing deep-water fisheries has been controversial (Sissenwine and Mace 2007). Catch per unit effort (CPUE) has shown relatively fast declines in several fisheries, raising concerns over their sustainability. The orange roughy (Hoplostethus atlanticus) provides an example of over exploitation of a poorly understood deep-water species under a scenario in which management implementation was compromised by a paucity of basic data (Francis et al. 1995, Clark et al. 2000, Clark 2001). Deep-water fisheries are consequently considered complex given the $k$-selected traits identified among a majority of species, including slow growth, high longevity, and late maturity (Norse et al. 2012). The potential for exploitation remains, but detailed data on species life histories, including residency, movement, and migration patterns that define stock units is required for robust management.

When compared to temperate and tropical ecosystems, the Arctic represents a relatively untouched region for fisheries exploitation, given its remote and hostile location and inaccessibility due to landfast ice (Christiansen et al. 2014). The region is therefore considered promising for fisheries development, especially with receding ice cover as a result of global climate change (MacNeil et al. 2010). As a result, there are mounting concerns over fisheries development related to the lack of basic biological data and our understanding of the ecosystem as a whole (Christiansen et al. 2014). At present, one of the primary species that is fished in the Arctic is Greenland halibut (Reinhardtius hippoglossoides), a deep-water fish of high commercial value that is long lived (i.e., $k$ selected; Gregg et al. 2006, Treble et al. 2008). Greenland halibut typically occur at depths between 200 and $2000 \mathrm{~m}$ and are distributed throughout the northwest and northeast Atlantic and northern Pacific Oceans (Scott and Scott 1988, Bowering and Chumakov 1989, Bowering and Brodie 1995, Treble and Jorgensen 2002). In Baffin Bay and Davis Strait, Canadian and Greenlandic commercial fisheries target this species in offshore waters (Jørgensen and Treble 2015), while community-based commercial fisheries also operate in coastal regions of Greenland and to a lesser extent Canada (Dennard et al. 2010, Jørgensen and Hammeken Arboe 2013, Nygaard and Boje 2013).

The Greenland halibut fishery in Cumberland, southeast Baffin Island, represents the only Inuit communitybased fishery for this species in Canadian waters (Pike 1994) and provides a potential model for fisheries development in the region to address high unemployment and limited economic initiatives. It was first established in 1987 and is a coastal ice-based fishery that operates in the inner northern section of the Sound (Fig. 1). To inform management, a standard tag-recapture study was undertaken in Cumberland Sound in 1994 and from 1997-2000 to better understand Greenland halibut movement patterns (Treble 2003). Fishing effort was relatively low and returns were limited; however, the results indicated that Greenland halibut located in the northern winter fishing grounds were resident, while fish tagged near the mouth of Cumberland Sound were migratory to offshore waters (Treble 2003). These observations suggested an isolated inshore stock of fish is present in the northern portion of the Sound, similar to that observed in western Greenland fjords (Boje 2002; i.e., a sink population, originating from the offshore but resident in Cumberland Sound). Based on available data, the Northwest Atlantic Fisheries Organization (NAFO) Scientific Council advised that a separate stockmanagement area could be established within the traditional Inuit winter fishing grounds in Cumberland Sound (NAFO SC 2004). This resulted in the designation of the Cumberland Sound Management Boundary (CSMB) that encompassed the northern section of the Sound and included the limit of land-fast ice and all known winter fishing locations since the fishery began (Fig. 1). The existing inshore allocation or total allowable catch (TAC) of Greenland halibut was assigned to this new management area. In 2009 and 2010, a trial summer fishery was started in the deeper portions of Cumberland Sound overlapping the CSMB (Young 2010) and, in 2010 and 2011, commercial fishing took place in the NAFO Division $0 B$ region of the Sound, south of the CSMB (Fig. 1b). These test and commercial fisheries, using large offshore vessels (14.9-27.1 m length) and fishing more intensively than during the winter fishery, reported good catches of Greenland halibut indicating the potential for the growth of a summer commercial fishery in the southern region of the Sound. These findings raised questions over the stock affinity of fish found in the northern and southern regions of Cumberland Sound and the potential impact that a summer fishery would have on the current winter fishery.

The overall objective of the current study was to examine the spatial and temporal movement patterns of a deep-water commercially important fish species to elucidate residency and migration patterns in relation to Arctic fisheries management boundaries and TACs. While traditional tag-recapture data have revealed complex and large-scale movements of Greenland halibut (for example, Boje 2002, Treble 2003, Albert and Vollen 2015), these data typically lack sufficient detail to resolve management planning because they provide only a start and end point with no temporal data on spatial use. Through recent technological advancements, telemetry tools can now document the intricate movements and migration patterns of animals, generating novel insights in this difficult-to-study environment (Hussey et al. 2015). Importantly, these data are beginning to provide a cornerstone for fisheries management (Welch et al. 2014, Espinoza et al. 2015, Raby et al. 2015), but to date, only a handful of studies have examined 


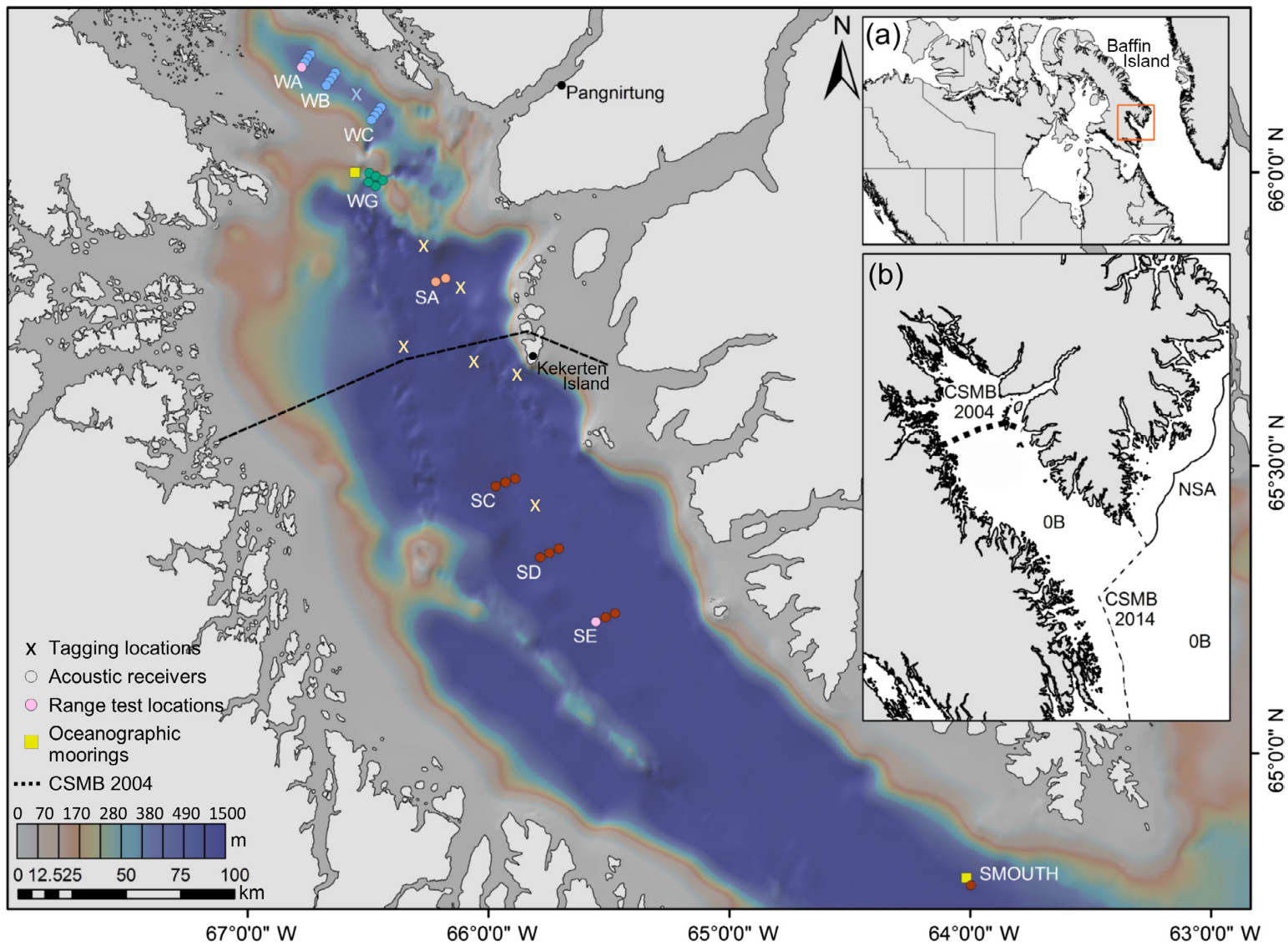

FIG. 1. Map of the study site within Cumberland Sound. Circles indicate the locations of individual acoustic receivers, where red identifies receivers located in the southern, deep-water environment; light red are receivers located in the deep water area north of the Cumberland Sound Management Boundary (CSMB); blue are receivers located in the northern, shallow-water environment; and green are receivers forming a gate across a deep-water channel dividing the shallow and deep-water regions. The label next to each row of receivers indicates the name of those stations. The locations of fixed oceanographic moorings, range tests and the CSMB established in 2004 are shown. Fish tagging locations are marked with X; yellow X are Greenland halibut tagged in August 2010 and 2011, and blue X is Greenland halibut tagged in April 2012. Inset (a) indicates the location of Cumberland Sound on the southeast side of Baffin Island, Nunavut, Canada. Inset (b) indicates fisheries and resource management boundaries in the region. The location of the CSMB in 2004 is designated with a thick dashed line within Cumberland Sound, and the relocated boundary (CSMB 2014) is shown by a thin dashed line connected to the Nunavut Settlement Area (NSA), a 12-nautical-mile (22.2 km) offshore boundary reserved exclusively for indigenous fishing rights. Northwest Atlantic Fisheries Organization (NAFO) management Division 0B (Southern Cumberland Sound prior to 2014 and Davis Straight) are also indicated. [Color figure can be viewed at wileyonlinelibrary.com]

movements of deep-water species due to the constraints of available technology (Priede and Bagley 2000, Afonso et al. 2012, Weng 2013). Through the first application of acoustic telemetry at depths $>1000 \mathrm{~m}$, Greenland halibut were tagged in both the Cumberland Sound Turbot Management Area (the area of the Inuit winter fishery north of the CSMB) and the Division 0B portion of the Sound (the region south of the CSMB that that extends into the offshore; Fig. 1), and tracked over a 12-month period. A collaborative effort among research scientists, fisheries managers, and an Inuit community, the study (1) quantified the movements of Greenland halibut to assess whether the CSMB encompasses a discrete sink population, (2) examined environmental and biological factors driving observed fish behavior, and (3) assessed the utility of acoustic telemetry for generating rapid data to inform fisheries management in deep-water ecosystems

\section{Methods \\ Study site}

Cumberland Sound is a large $(\sim 350 \times 150 \mathrm{~km})$ inlet located on the southeast coast of Baffin Island $\left(65^{\circ} 20^{\prime} 02^{\prime \prime} \mathrm{N}, 66^{\circ} 00^{\prime} 50^{\prime \prime} \mathrm{W}\right.$; Fig. 1). The bathymetry of the Sound consists of shallow water margins encompassing a deep-water channel in the central region. The deep-water channel can be broadly divided into two bathymetric zones, the northern sector where maximum depths reach $\sim 600 \mathrm{~m}$ and the southern sector where depths average $\sim 1000 \mathrm{~m}$, interspersed with isolated deep-water pockets 
that reach $\sim 1400 \mathrm{~m}$, forming a mountainous terrain. The entrance of the Sound consists of a sill at $\sim 300 \mathrm{~m}$ that divides the deep-water channel and shallower peripheral margins from Davis Strait (Fig. 1). Climatic and sea conditions in the Sound are characterized by two distinct seasonal periods, winter land-fast ice between late October and May and a summer open-water period (JuneOctober), although, during the winter, the central and southern areas of the Sound largely consist of drifting pack ice and at times open water.

\section{Acoustic array design and deployment}

To determine the residency and movement patterns of Greenland halibut, an array of VR2W-69 kHz acoustic receivers was deployed and a combination of $\mathrm{V} 16-6 \mathrm{H}$, V16-4H, and V13-4L acoustic tags (VEMCO, Halifax, Nova Scotia, Canada) were surgically implanted in fish. Acoustic receivers were fixed to rope risers; each riser had a subsurface float (750 or $1500 \mathrm{~m}$ depth rated) at one end and was attached to a $90.7 \mathrm{~kg}$ circular cast iron anchor via an acoustic release (ORE offshore; EdgeTech, West Wareham, Massachusetts, USA) at the other end. Moorings were deployed at an average depth of $1056 \mathrm{~m}$ (range 882-1198 $\mathrm{m}$ ) in the southern area, and $387 \mathrm{~m}$ (range 149-486 m) in the northern area. The rope risers connecting the releases to the subsurface float were 187 and $12 \mathrm{~m}$ in length in the southern and northern regions, respectively, reflecting the depth difference between regions. In the southern deep-water area, $2 \mathrm{~m}$ chain sections connected the acoustic release to the anchor through a swivel attachment, while in the northern region, a 2-m rope section was used. All VR2W receivers were attached $1 \mathrm{~m}$ below the subsurface float oriented with the hydrophone pointing downward. The array was specifically designed to provide coverage in four main regions of Cumberland Sound: (1) 11 monitors were deployed in the deep southern region south of the CSMB including one on the sill at the entrance to the Sound (SC, SD, SE, and SMOUTH); (2) two monitors were deployed at the most northern point of the deep southern region, north of the CSMB (SA); (3) five monitors were deployed in a gate across a deep-water channel connecting the southern and northern regions (WG); and (4) 14 monitors were deployed in the shallower northern region (WA, WB, WC; Fig. 1). All acoustic moorings were deployed in mid July 2011 and recovered at the end of August 2012 following an approximate 12-month deployment.

\section{Fish capture and tagging}

Greenland halibut were captured on bottom longlines set at $\sim 900-1100 \mathrm{~m}$ depth in the southern region and $\sim 400-600 \mathrm{~m}$ depth in the northern region. In the southern region, fishing was conducted aboard a commercial fishing vessel in August 2010 and the Nunavut Government research vessel, the Nuliajuk, during August
2011. In both years, longlines were $\sim 400-2000 \mathrm{~m}$ in length with 200-2000 gangions of 0.3-3.0 m length and size 14-16 Mustad Duratin circle hooks (O. Mustad and Sons A.S., Gjövik, Norway) baited with frozen squid (Argentine Illex). In the Northern region, bottom longlines were set through ice holes in April 2012 following traditional community fishing practices; see Dennard et al. (2010) for specific details. During all fishing, longlines were soaked for $\sim 12 \mathrm{~h}$.

Following soak, longlines were hauled to the surface and fish in good condition were selected for tagging. During the summer period, fish were either processed immediately or held in a large tank with continuous flowing seawater for a maximum of $1 \mathrm{~h}$; in the winter fish were processed directly during longline retrieval. All fish were measured (fork length, FL) and a small incision was made into the peritoneal cavity on the non-ocular dorsalventral surface. Tags (type and [nominal delay in seconds]: V16-6H [90], V16-5H [90], V16-4H [300] and V13-1L [110 and 300]; number of tags deployed 20, 10, 178, and 15, respectively) were inserted lateral to the length of the fish and the incision was closed using three to four interrupted sutures (Ethicon VCP443, 2-0, FS-1 cutting; Somerville, New Jersey, USA). Fish were released following the insertion of an external marker tag (FLOY Tag, Seattle, Washington, USA) at the base of the dorsal fin. Tags and all surgical equipment were washed in betadine and the dorsal-ventral surface was swabbed with a $10 \%$ diluted betadine solution prior to making the incision (Fig. 2). No anesthetic procedures were used given that flatfish require a large dosage of MS222 and consequently recovery times are too long and the health of the fish may be compromised. Fish placed ocular surface down remained calm during all procedures $(<10 \mathrm{~min})$ and swam off strongly following release.

\section{Acoustic range testing}

To determine the effective range of acoustic receivers and tags implanted in fish, two range tests were performed in each of the southern $(\sim 1000 \mathrm{~m})$ and northern ( $\sim 450 \mathrm{~m}$ ) regions over the study period (July 2011-August 2012; WA and SE; Fig. 1). Specific details of the range test design and a summary of the results are included in Appendix S1.

\section{Environmental monitoring over sampling period}

Bottom temperature and dissolved oxygen were recorded at two oceanographic moorings located in the northern (272 $\mathrm{m}$ depth) and southern regions $(475 \mathrm{~m}$ depth) throughout the study (Fig. 1; see Bedard et al. 2015). Near-bottom temperature was collected using an RBR (Ottawa, Ontario, Canada) TR-1050 thermistor and near-bottom dissolved oxygen using a RBR DO-1050. Both instruments were calibrated prior to deployment and set to sample every minute. Accuracy of the temperature sensor was $\pm 0.002^{\circ} \mathrm{C}$ and the dissolved oxygen 


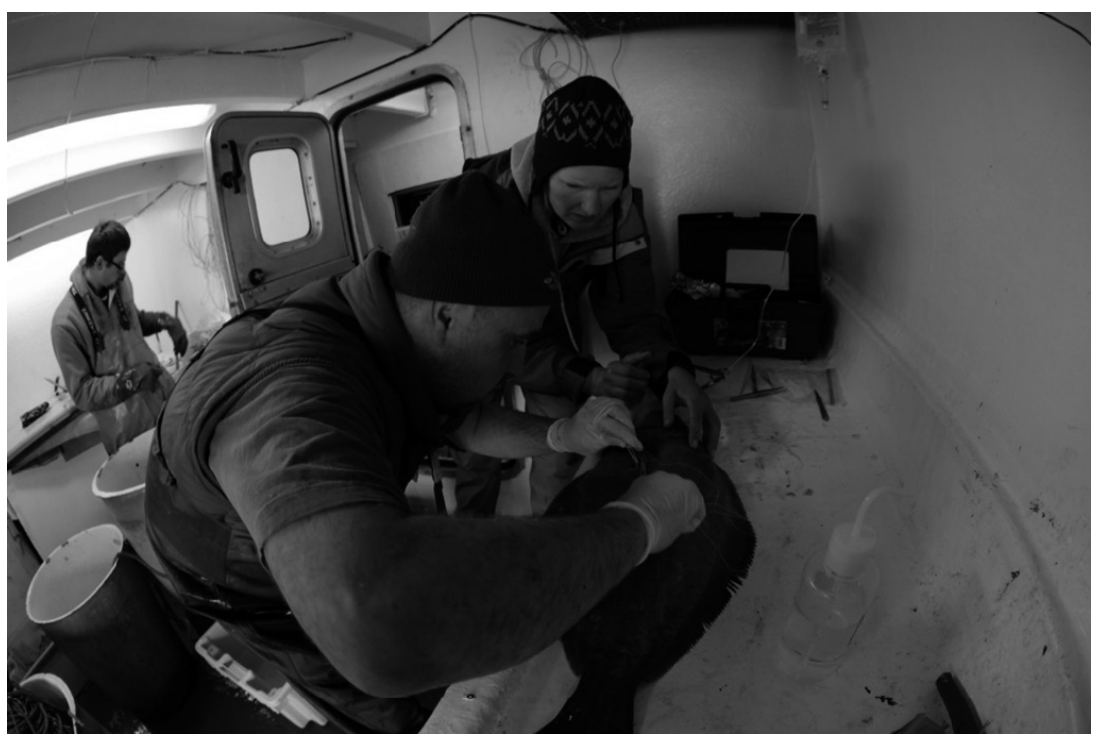

FIG. 2. Photograph of the tagging procedure involving the surgical implantation of acoustic tags, with life spans of 5-10 yr, into the peritoneal cavity of Greenland halibut prior to their release.

sensor $\pm 2 \%$. Ice cover data (\%) for the period of monitoring were obtained from the Canadian Ice Service archive (data available online). ${ }^{8}$ To define ice cover for the shallower northern and deeper southern regions, data for Cumberland Sound were first isolated and the southern deep-water region divided from the shallower northern region by a straight line between Imigen and Kekertukdjuak Islands (Appendix S2). Ice cover for each region (north and south) was then calculated using the total concentrations of ice (reported in tenths for each region) multiplied by the percent area that concentration represents out of the total area of the focal region to provide a weighted average. Weighted ice cover data were then summed to provide percent ice cover per week for the entire focal region. Data for daily photoperiod (h), and wind speed $(\mathrm{km} / \mathrm{h})$ were obtained from Environment Canada (available online) and moon phase (illumination scale $0-1$ ) from Time and Date AS (available online). ${ }^{9}, 10$

\section{Time series of ice data}

In addition to ice cover data for the study period, ice data were extracted for the months the community winter fishery operates (January-May) and for each year from its establishment in 1987 through 2014. Specifically, we estimated percent landfast ice cover to examine long-term trends in sea ice extent as a measure of fishers' accessibility to their fishing grounds. Landfast ice cover (\%) was calculated for the community fishing area (i.e., the region north of the CSMB; Appendix S2) as the area of landfast and $10 / 10$ concentration ice divided by the total area north of the CSMB. For the years 1987-2007, ice data

\footnotetext{
8 https://www.ec.gc.ca/glaces-ice/

$9 \mathrm{http}: / /$ weather.gc.ca/index_e.html

10 www.timeanddate.com
}

were available on a monthly basis, whereas after 2007, weekly ice data were used.

Time series of CPUE and fishing locations for the Cumberland Sound community-based ice fishery

To monitor catch and effort trends, Fisheries and Oceans Canada has provided fishermen with logbooks since 1991; however, the return of these logbooks has not been mandatory. These logbook data include the number of longlines set, longline soak time, the number of deployed hooks, the number of hooks lost during a set, the number of fish caught in a set, fisher identification and fishing location (latitude and longitude or position marked by hand on a printed map). Hand-marked positions were digitized using a georeferenced digital version of the printed map. To examine temporal trends in CPUE of the fishery, CPUE was calculated as follows:

$$
\mathrm{CPUE}=\frac{f}{H_{\mathrm{s}}-H_{\mathrm{L}} / S_{\mathrm{D}}}
$$

where $f$ is the number of fish caught in a given set, $H_{\mathrm{s}}$ is the number of hooks per longline set, $H_{\mathrm{L}}$ is the number of hooks lost per longline set, and $S_{\mathrm{D}}$ is the number of hours between set deployment and retrieval (soak time). Previous examinations of CPUE patterns in the Cumberland Sound Greenland Halibut fishery found significant relationships between catch and both the number of hooks fished and soak time (Pike 1994, DFO 2008), although the relationships were highly variable in space and time. We opted to include soak time in the CPUE calculation as, although this can make the values susceptible to error due to gear saturation, only 87 out of $>7000$ reported sets have recorded more than 50 fish per 100 hooks over the history of the fishery. In contrast, 
excluding soak time from the CPUE calculation, given the identified relationship, would affect the relative weighting of short and long sets in the overall CPUE calculation. Data on CPUE prior to 1991 were extracted from Pike (1994). Locations of fishers over time were examined to determine consistency in location of fishing relative to landfast ice cover and CPUE data.

Due to the non-mandatory nature of the monitoring program, logbook return rates have varied through time resulting in inconsistencies in the frequency and quality of records (how often the logbooks are submitted and the completeness of data entry), consequently these data represent general CPUE and fisher location trends rather than absolute values for the entire fishery over time (see Appendix S3 for further data).

\section{Data analyses}

Acoustic telemetry data were first screened to identify false tag detections produced as a result of environmental sounds or tag collisions (Heupel et al. 2006, Simpfendorfer et al. 2015). Filtering was then undertaken using the WhiteMihoff Filtering Tool (White et al. 2014) to isolate detections of individual fish that occurred $\geq 1 \mathrm{~h}$ apart to identify any spatially unrealistic detections (fish that moved large distances above that of their sustained swimming speed) and/or were detected on multiple receivers in different locations, at the same time. These potential false detections were then manually screened to determine validity.

Detection data for each fish were plotted by date and region of occurrence (southern deep-water section, northern-most area of southern section located north of the CSMB, the gate, and the northern region; see Methods: Acoustic array design and deployment). Example movement behaviors of individual Greenland halibut based on their occurrence in the four defined regions of Cumberland Sound were then visualized using gradient bubble plots of percentage of detections at each monitor relative to total number of detections for that fish and color coded by season (open water summer 2011, ice-covered winter 2012, and open water summer 2012). Winter- and summertagged fish were plotted independently to determine if fish tagged at each location (north and south) and season (summer and winter) undertook consistent residency/ movement patterns.

A residency index (RI) was calculated to examine seasonal residency and movement patterns of all tagged Greenland halibut within Cumberland Sound over the 1 -yr period relative to the CSMB (management significance) and the deep-water and shallow-water regions (ecological significance). The RI was calculated as the number of days individual fish were detected on each receiver within the array divided by the total number of days respective fish were detected across the entire array. RI values range from 0 to 1 , with 1 indicating $100 \%$ residency at a particular receiver and values near zero low residency near any given receiver. This measure was used instead of raw data to remove bias associated with a higher number of detections on a monitor when only a few fish were present or a few detections tied with a large number of individual fish. These RI values were plotted by month and monitor location (from furthest north to furthest south) to examine fish spatial and temporal RI trends. As above, winter- and summer-tagged fish were plotted independently. RI data were overlaid over time series data for bottom sea temperature, percent ice cover, and bottom oxygen to visually examine correlations between RI and key environmental variables. To examine potential factors driving the observed daily residency/ movement patterns of Greenland halibut in shallower vs. deeper water regions of Cumberland Sound, generalized linear mixed models (GLMM) with binomial error structure and a logit link function were constructed (Bond et al. 2012, Lédée et al. 2015). For this purpose, Greenland halibut presence/absence was determined each day throughout the study period from 1 September 2011 to 31 August 2012 where a value of 1 was assigned for days present and 0 for days absent. Two separate models were used to independently test for presence/absence of Greenland halibut at receivers (binary variable) in the shallow northern and deep southern regions respectively, relative to environmental and biological parameters (continuous predictor variables). The fixed environmental parameters were averages of daily wind speed and direction, photoperiod, moon phase, percent ice cover, bottom sea temperature, and bottom dissolved oxygen concentration; the biological parameter was fish size (fork length, FL [cm]). Greenland halibut ID and initial tagging location (southern and northern regions) were included as random effects to account for repeated measures in the data. Continuous predictor variables were screened for collinearity prior to analysis using a Pearson's correlation coefficient $(\leq 0.6)$ and variance inflation factors $(<3.0)$. Most covariates were not collinear, except for month, which was highly correlated with percent ice cover $(0.74)$ and was therefore removed prior to analysis. The GLMM was fit using the glmmPQL function in the MASS $\mathrm{R}$ package with a first-order autoregressive function to account for temporal autocorrelation in presence/absence and an $\alpha$ of 0.05 . Model fit was assessed by calculating the marginal $r^{2}$ (solely fixed effects) and conditional $r^{2}$ (both fixed and random effects) using the methods described by Nakagawa and Schielzeth (2013). Raw acoustic detection data used in all the above analyses are available online through the Ocean Tracking Network Publication Data Repository (Hussey 2016).

Data on CPUE in the winter fishery and percent landfast ice cover in the northern area delineated by the CSMB were plotted against time since the development of the fishery. Two defined linear relationships were present in each data set, consequently piece-wise regression was used to examine temporal trends (Crawley 2007). Following an iterative searching approach, the data were modeled as follows:

$$
y \sim x * I(x<c)+x * I(x>c)
$$


where $c$ is the breakpoint, ${ }^{*}$ is the main effects and interactions and $I(x<c)$ and $I(x>c)$ are essentially dummy variables dividing the breakpoint in the data to model two sets of regression parameters. To estimate $c$, endpoint values surrounding the visual break point were selected and linear regression was fitted to consecutive breakpoint values within the defined range to identify regression parameters with the lowest mean square error.

To quantify annual fisher locations over the time of the fishery, the Bayesian estimate of the standard ellipse area using individual fisher locations per year, were calculated following the methods proposed by Jackson et al. (2011). The standard ellipse represents bivariate data estimated from the covariance of the longitude $(x)$ and latitude $(y)$ data. Each annual ellipse contains approximately $40 \%$ of the data representing the core fisher locations and accounts for variable sample sizes across years. All statistical analyses were conducted using $\mathrm{R}$ v.3.1.2 (R Development Core Team 2014).

\section{RESUlts \\ Tagged Greenland halibut}

A total of 223 fish were tagged (182 in the southern deep water region and 41 in the northern shallower water region) ranging in size from 48 to $96 \mathrm{~cm}(69.8 \pm 0.1 \mathrm{~cm}$ $[$ mean $\pm \mathrm{SD}])$. Mean size was larger for fish tagged in the southern region $(72.5 \pm 8.5 \mathrm{~cm})$ than those tagged in the northern region $\left(64.5 \pm 7.1 \mathrm{~cm} ; T_{61.55}=4.6, P<0.001\right)$. Of all tagged fish, $167(74.2 \%)$ were detected; 134 and 31 individuals tagged and released in the south, and north, respectively. The number of detections per fish ranged from 1 to 8846 with a mean of $732.1 \pm 1179.8$ and a total number of 122252 detections across the entire array (Fig. 3). When considering detection filtering, no false ID tags were found and of the 676 possible false detections identified by the White-Mihoff filter, all detections were either on the same monitor or on an adjacent monitor and consequently deemed viable given the species life history. Range testing found that deep-water monitors detected $>60 \%$ of V16 tag transmissions at the furthest distance tested of $802 \mathrm{~m}$, while V13 tags had an effective detection range of $308 \mathrm{~m}$ (Appendix S1). For the shallowwater moorings, the effective detection range was approximately $290 \mathrm{~m}$ and $273 \mathrm{~m}$ for V16 and V13 tags, respectively; however, this test was compromised by bottom topography (see explanation of possible issues with this test in Appendix S1).

\section{Individual Greenland halibut movements}

For southern-tagged fish, individual movement patterns were broadly divided into four behavioral types: (1) fish that remained in the southern deep water region south of the CSMB and were principally detected during open-water periods ( $n=37,27.6 \%$; Figs. 3a, 4a); (2) fish detected only in the southern region but including the northernmost monitors north of the CSMB $(n=64$, $47.8 \%$; Figs. 3a, 4b); (3) fish detected in the south and at the gate ( $n=22,16.4 \%$; Figs. 3a, 4c); and (4) fish detected in all regions (south, gate, and north; $n=9,6.7 \%$; Figs. 3a, $4 d)$. For individual fish displaying behaviors (2-4), detections followed a distinct seasonal south-north-south movement (Fig. 3a). For the northern-tagged fish, three key movement behaviors were evident: (1) fish only detected in the northern region predominantly during the ice cover period ( $n=16,48.5 \%$; Figs. $3 \mathrm{~b}, 5 \mathrm{a})$; (2) fish detected only at the gate $(n=5,15.2 \%$; Figs. $3 \mathrm{~b}, 5 \mathrm{~b})$; and (3) fish detected in all three regions $(n=8,24.2 \%$; Figs. 3 b, $5 \mathrm{c}, \mathrm{d})$. A total of $52 \%$ of northern-tagged fish were detected outside of the northern region and movements followed the same spatial seasonal pattern as southerntagged fish (Fig. 3b).

\section{Greenland halibut residency index within the Sound}

During the open-water summer period of 2011, all southern-tagged fish occurred in the deep-water southern region (Fig. 6a), with RI values ranging from 0.01 to 0.45 $(0.1 \pm 0.08$ [mean $\pm \mathrm{SD}])$ and the highest monthly RI values were recorded at monitor locations SA2 (0.45), SE3-R3 (0.23), SE1 (0.18), and SA2 (0.25) in August, September, October, and November, respectively (Fig. 6a). The majority of these fish were detected south of the CSMB (monitor locations SC-SE and SMOUTH; Fig. 6a). Between December 2011 and February 2012, fish were present in the southern and northern regions as they transitioned northward (Fig. 6a). Following this transition period, RI values for the core winter period (March to May) ranged from 0.002 to $0.29(0.07 \pm 008)$ with maximal values recorded in the deep channel connecting the two regions (March, WG4 $=0.29$; April, $\mathrm{WG} 2=0.27)$ and the northernmost deep-water section (May, SA3 $=0.26$ ), both areas north of the CSMB. In June, fish transitioned southward, with most fish resident in the southern deep-water region during July and August (RI range 0.02-0.36; $0.10 \pm 0.08$ [mean $\pm \mathrm{SE}$ ]; maximal values July, SA2 $=0.36$ and August, SE3-R2 $=0.23$; Fig. 6a). Greenland halibut tagged in the northern fishing ground showed similar temporal and spatial RI patterns to those tagged in the south (Fig. 6b). In April and May, the highest RI values recorded were at WG4 (0.28) and SA3 (0.44) north of the CSMB, while maximal RI values in June (SE2 and SE3-R3 = 0.26) and August (SE1 = 0.29) were located south of the CSMB (Fig. 6b).

\section{Generalized linear mixed models}

The GLMM for Greenland halibut presence/absence at receivers in the southern deep-water region found that fish detections decreased with increasing sea-ice cover, bottom dissolved oxygen concentrations, moon illumination, and body size; all other predictor variables were nonsignificant within the model (Fig. 7a, c, e, Table 1). For the shallow water northern region, the GLMM 


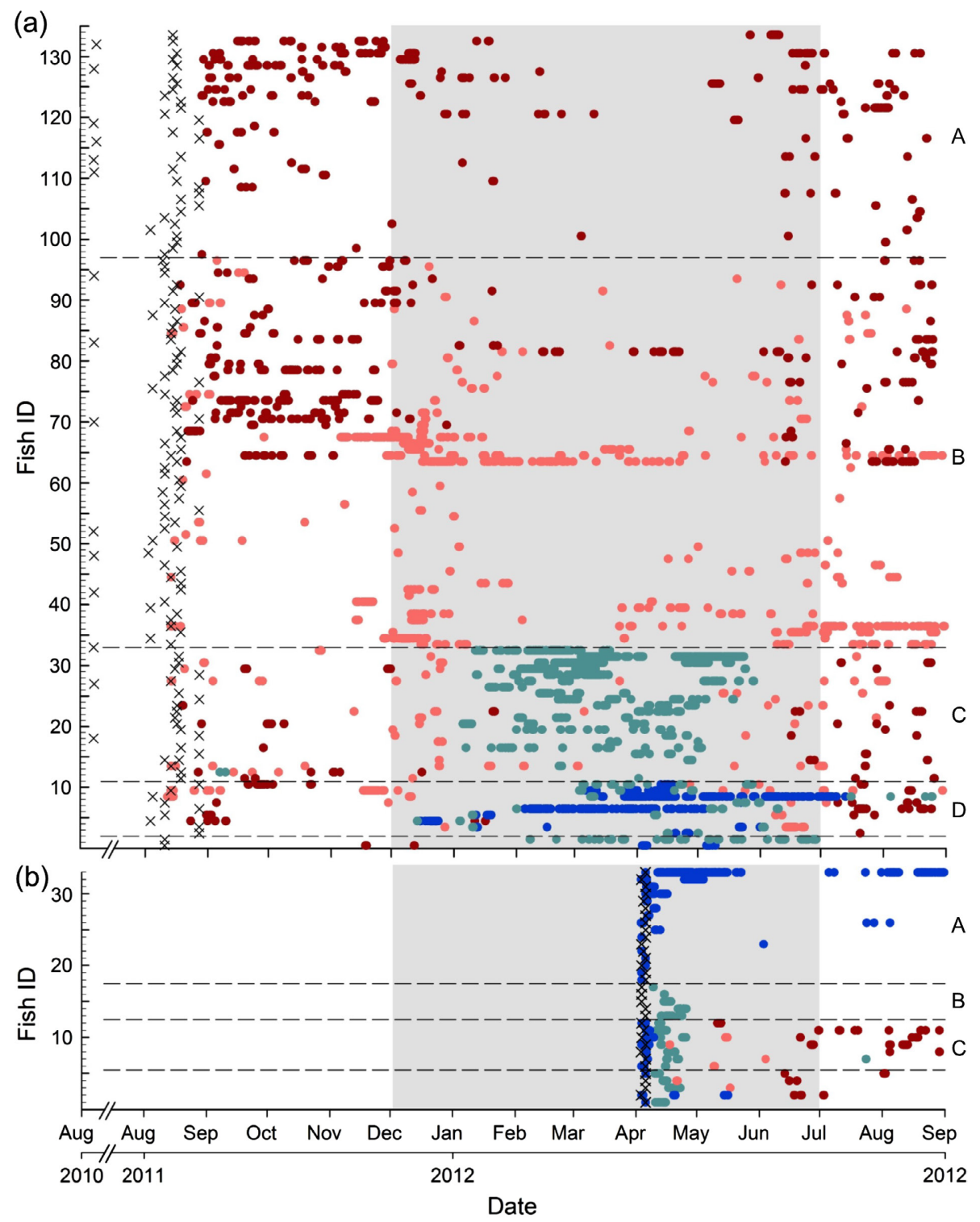

FIG. 3. Total detections of all Greenland halibut tagged and detected in Cumberland Sound. Black X marks the date each individual fish was tagged. Red dots are detections on deep-water receivers south of the Cumberland Sound Management Boundary (CSMB); pink dots are detections on deep-water receivers north of the CSMB; green dots are detections on the gate dividing the deep water southern and shallower northern regions; and blue dots are detections on the most northern shallower receivers. The gray shaded area indicates months during which the Sound was predominantly ice covered. Note the scale break on the $x$-axis between August 2010 and August 2011. (a) Greenland halibut tagged in the southern region of Cumberland Sound during the openwater period in August 2010 and 2011. Greenland halibut that were tagged in section A remained south of the CSMB $(n=37$, $27.6 \%)$, those in section B were detected in the southern region and also on the northernmost monitors north of the CSMB $(n=64$, $63.4 \%)$, those in section $\mathrm{C}$ were detected in the south and at the gate between north and south regions $(n=22,16.4 \%)$ and those in section $\mathrm{D}$ were detected in all regions (south, gate, and north; $n=9,6.7 \%$ ). The last two fish, depicted at the bottom of the panel, did not fit into any of the above categories. (b) Greenland halibut tagged in the northern region of Cumberland Sound in April 2012, where fish that were tagged in section A were only detected in the northern region $(n=16,48.5 \%)$, in section B were only detected on the gate $(n=5,15.2 \%)$, and in section $\mathrm{C}$ were detected in all three regions $(n=8,24.2 \%)$. The four Greenland halibut below line $\mathrm{C}$ did not fit into any of these discrete categories. [Color figure can be viewed at wileyonlinelibrary.com]

estimated that fish presence was associated with higher sea ice cover and higher bottom dissolved oxygen concentrations (Fig. 7b, d). There was a significant negative relationship observed between fish presence and bottom temperature indicating fish were not detected at the higher temperature range (Fig. 7e). There was no effect of wind speed and direction, moon illumination, or body size on fish presence/absence at receivers (Table 2). Both fixed and random effects accounted for most of the variation explaining Greenland halibut presence/absence at receivers in the northern region (marginal $r^{2}$ of 0.64 and a conditional $r^{2}$ of 0.85 ; Table 1 ) and a moderate amount 

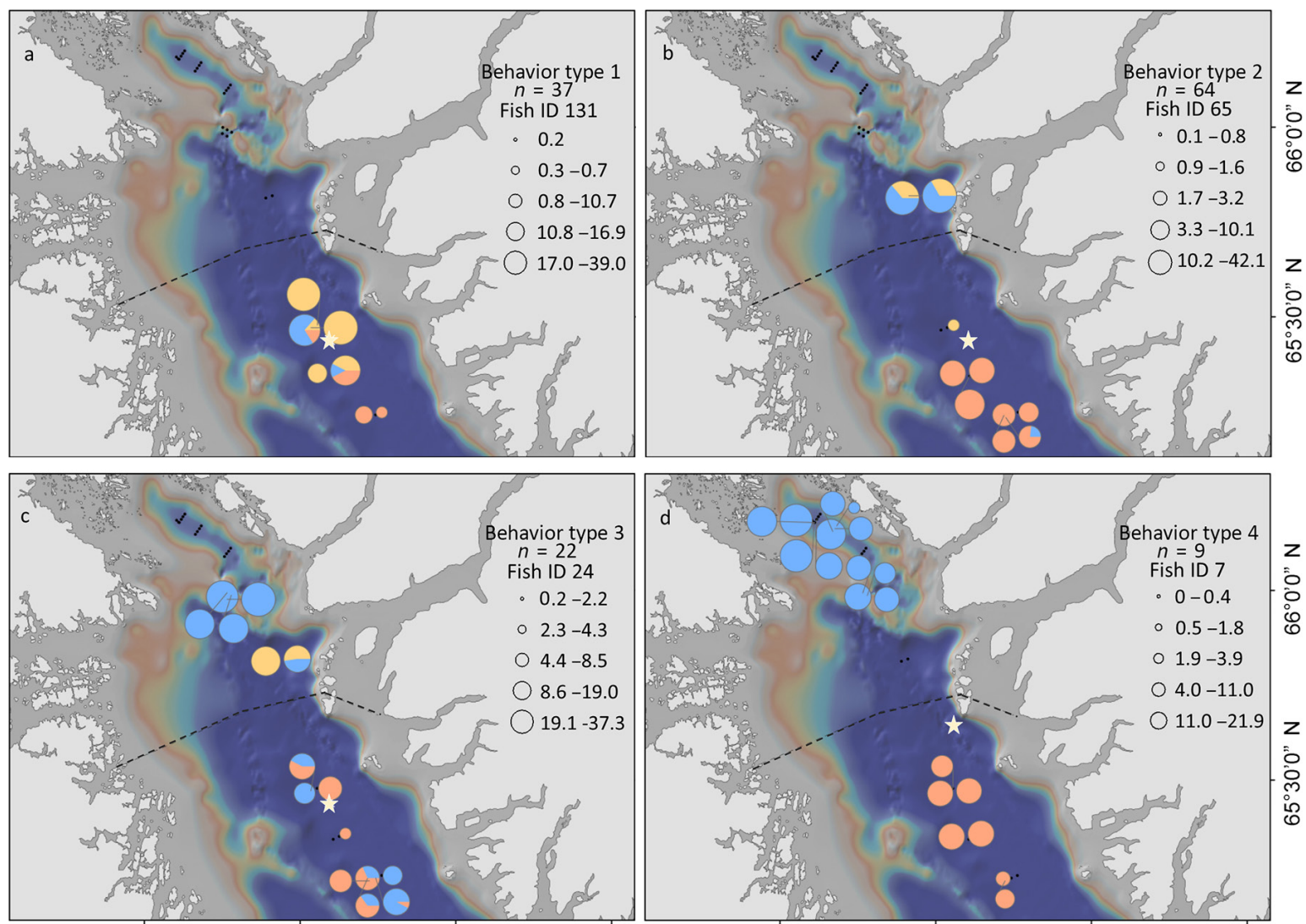

$67^{\circ} 0^{\prime} 0^{\prime \prime} \mathrm{W}$

$66^{\circ} 0^{\prime} 0^{\prime \prime} \mathrm{W}$

$65^{\circ} 0^{\prime} 0^{\prime \prime} \mathrm{W}$

$64^{\circ} 0^{\prime} 0^{\prime \prime} \mathrm{W}$

$67^{\circ} 0^{\prime} 0^{\prime \prime} \mathrm{W}$

$66^{\circ} 0^{\prime} 0^{\prime \prime} \mathrm{W}$

$65^{\circ} 0^{\prime} 0^{\prime \prime} \mathrm{W}$

$64^{\circ} 0^{\prime} 0^{\prime \prime} \mathrm{W}$

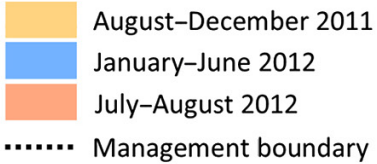

$\hat{\hbar}$ Tagging location

- Receivers without detections

Total detections (\%)

FIG. 4. Detection profiles of individual Greenland halibut tagged in the southern region of Cumberland Sound in August 2010 and 2011, showing the four representative behavioral types that were observed in this study. Pie charts on each map represent the proportion of detections (as a percentage of the total number of detections for that individual) on each unique receiver for the months August-December 2011 (open water), January-June 2012 (ice covered), and July-August 2012 (open water). The size of the pie chart varies dependent on the percentage of detections recorded for each receiver over the entire study period, with the data range displayed on the right side of each map. The star indicates the tagging location of each fish, and the Cumberland Sound Management Boundary (CSMB) is shown by a dashed line. (a) Greenland halibut ID 131, only detected in the most southern area of Cumberland Sound; (b) Greenland halibut ID 65, detected in the southern region as well as on the deep-water monitors north of the CSMB; (c) Greenland halibut ID 24, detected in both southern regions and at the gate; and (d) Greenland halibut ID 7, detected in $>3$ regions of Cumberland Sound. Note the detection profile scales are different for each behavior type. [Color figure can be viewed at wileyonlinelibrary.com]

of the variation for the southern region (marginal $r^{2}$ of 0.10 and conditional $r^{2}$ of 0.53 ; Table 2 ).

\section{CPUE fishery data, ice cover, and fisher locations}

The maximum reported catch rate of Greenland halibut in the fishery was $0.090 \mathrm{fish} \cdot \mathrm{hook}^{-1} \cdot \mathrm{h}^{-1}$ in 1987 , at the start of the fishery. The catch rate declined through the 1990s to a low of 0.014 in 1999, subsequently increased between 1999 and 2002 and then leveled off at an average catch rate of $0.040 \pm 0.010$ for the remaining period. The catch rate in 2013 was 0.057 fish $\cdot$ hook $^{-1} \cdot h^{-1}$ (Fig. 8). The initial decline in CPUE was correlated with an overall decrease in percent landfast ice cover within the fishing grounds (Fig. 8). Since 2002, the time period over which CPUE was relatively stable, average landfast ice cover of $68.4 \% \pm 0.1 \%$ was lower than that at the start of the fishery, but fluctuated on an annual basis between highs and lows of $92.7 \%$ and $50.2 \%$, respectively (Fig. 8). Piece-wise regression analysis identified a break point in both CPUE and landfast ice cover data in 2001. Prior to 2001, both CPUE and landfast ice cover showed a significant decline, while, after 2001, no significant relationship was found for either parameter (Fig. 8). When considering the location of fishers within the Sound, the fishery occurred at its most southerly point west of Kerketen Island in the deep-water region in 1987 (Fig. 9). Over 

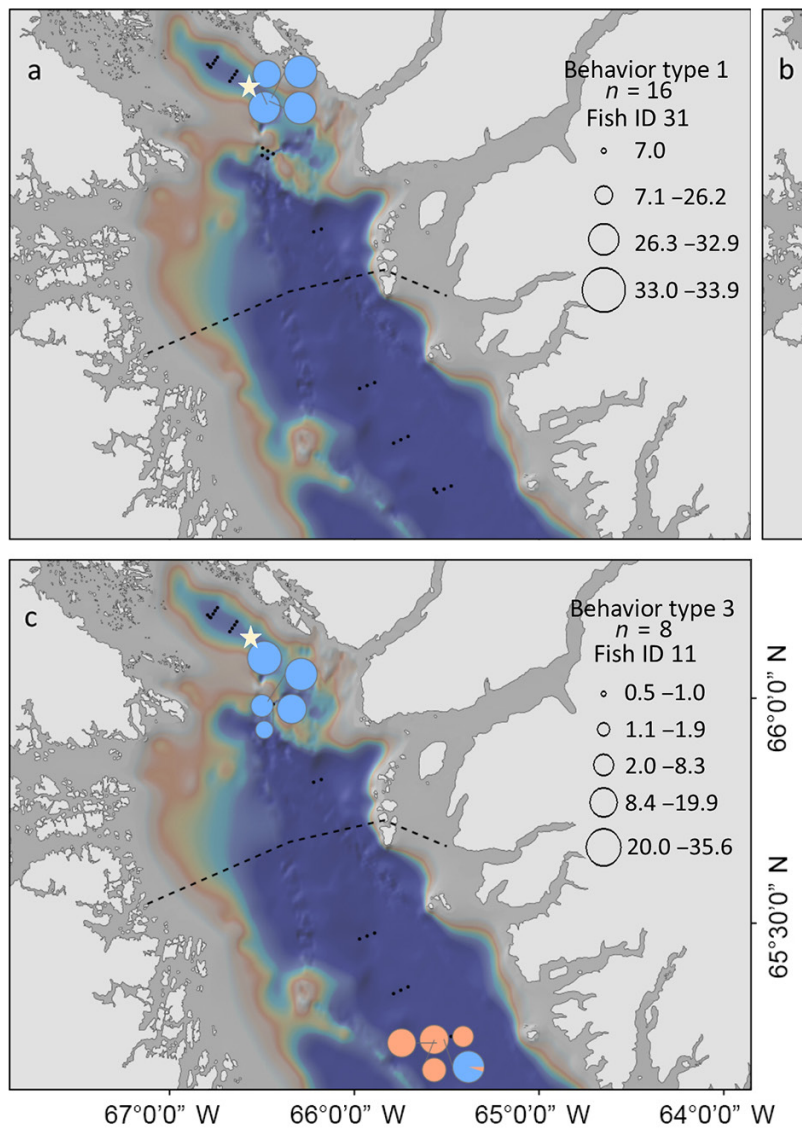

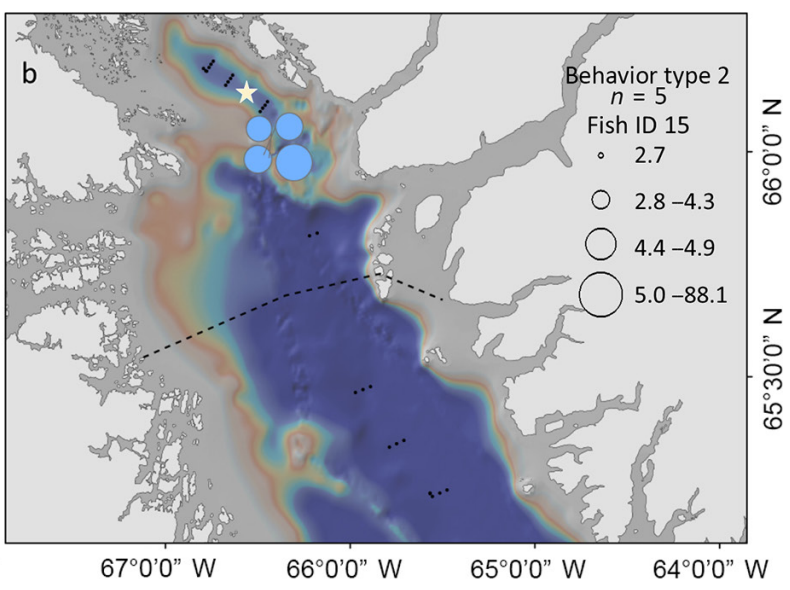

$z$
0
0
0
0
$z$
$z$
0
0
0
0
0
0

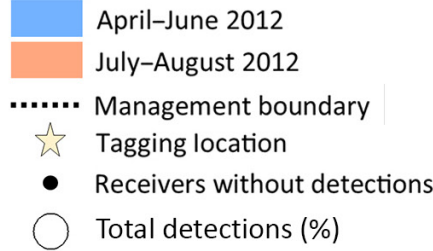

FIG. 5. Detection profiles of individual Greenland halibut tagged in the northern region of Cumberland Sound in April 2012, showing the three representative behavioral types that were observed in this study. Pie charts on each map represent the proportion of detections (as a percentage of the total number of detections for that individual) on each unique receiver for the months AprilJune 2012 and July-August 2012. The size of the pie chart varies based on the percentage of detections recorded for each receiver over the entire study period, with the data range displayed on the right of each map. The star indicates the tagging location of each fish, and the Cumberland Sound Management Boundary (CSMB) is shown by a dashed line: (a) Greenland halibut ID 31, detected only in the northern region of the Sound; (b) Greenland halibut ID 15, detected only on the gate connecting the northern and southern regions; and (c) Greenland halibut ID 11, detected in $>3$ regions. Note the detection profile scales are different for each behavior type. [Color figure can be viewed at wileyonlinelibrary.com]

subsequent years, the location of the fishers moved progressively northward, as ice concentration reduced and then fluctuated, and most recently fishers were located in the northern region near monitor lines WA and WB (Figs. 1,9).

\section{DisCusSion}

These data, the first of their kind for examining the long-term movements of fish at $\sim 1000$ m depth, demonstrate that a demersal fish, Greenland halibut, undertook seasonal movements within Cumberland Sound. Through linking telemetry and environmental data, sea ice cover was found to be the principal factor driving the observed movement northward into the inner Sound, but variability in movement behavior among individuals was recorded. Reductions in sea-ice extent north of the CSMB since the beginning of the fishery were associated with declining CPUE and the progressive northward changes in the location of the fishery over time. The seasonal movements of Greenland halibut across the CSMB have implications for the management of this fishery, specifically questioning the current location of the CSMB, and have led to its conditional relocation to the entrance of the Sound. In a broader context, these data demonstrate that acoustic telemetry can provide a rapid method to obtain detailed information on spatial and temporal residency and movement patterns of deep-water species to inform management. Given increasing interest in exploiting deep-water fish stocks in conjunction with rapid advancements in telemetry technology, it is anticipated that telemetry will provide an important tool for future monitoring of deep-sea ecosystems.

\section{Telemetry to understand the ecology of deep-water marine species}

The overall seasonal movement pattern of Greenland halibut within Cumberland Sound at 600-1000 m depth 

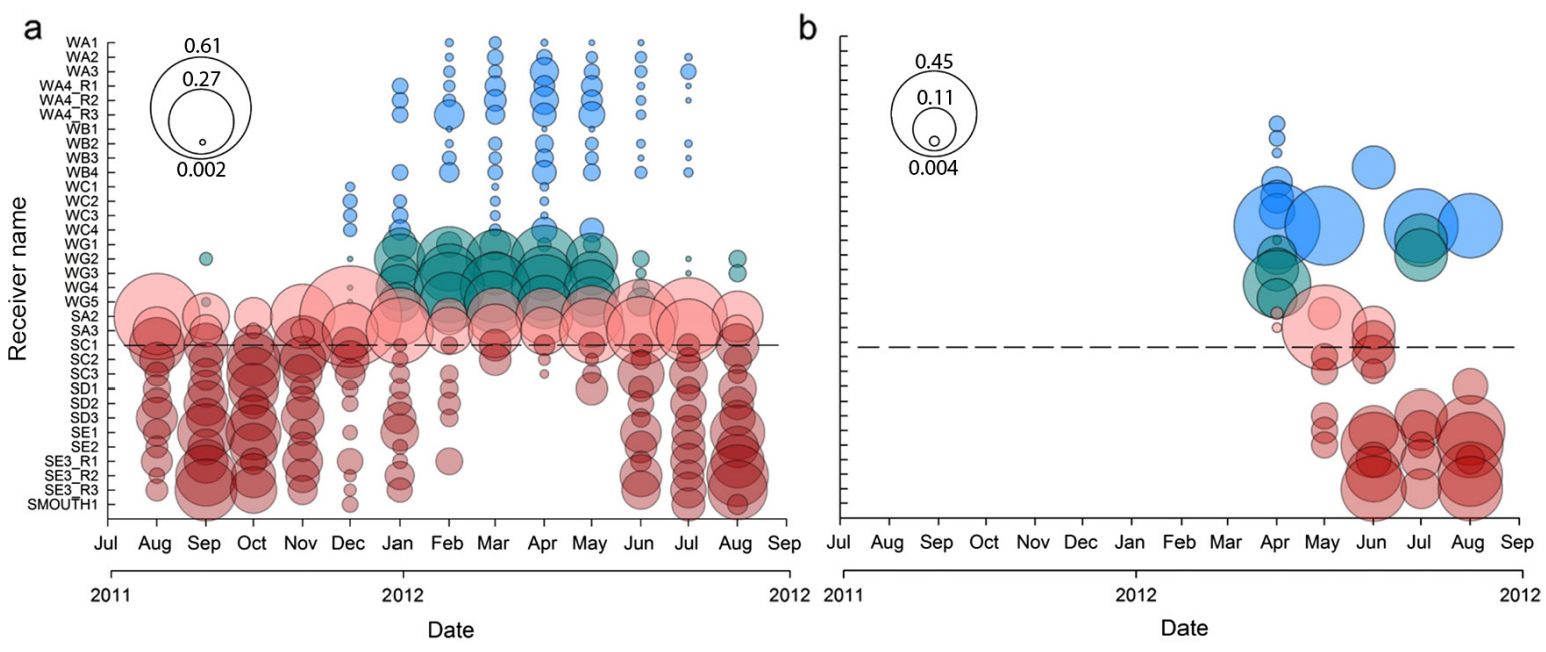

FIG. 6. Monthly residency index (RI) values associated with the detections of Greenland halibut at the specified acoustic receivers within Cumberland Sound. The area of each circle is representative of the RI, calculated as the number of days individual fish were detected on each receiver within the array divided by the total number of days respective fish were detected across the entire array. Red circles identify receivers that were located in the deep-water southern environment of Cumberland Sound, south of the Cumberland Sound Management Boundary (CSMB); pink circles are receivers located in the deep-water environment, but north of the CSMB; green circles are RI values for the gate receivers connecting the deep and shallower-water regions; and blue represents the shallower-water, northern-most receiver RI values. The black dashed line is the location of the CSMB, where receivers below the line are south of the CSMB, and receivers above the line are north of the CSMB. (a) RI values of Greenland halibut tagged in August 2010 and 2011 in the southern region of Cumberland Sound; (b) RI values of Greenland halibut tagged in April 2012 in the northern region of Cumberland Sound. [Color figure can be viewed at wileyonlinelibrary.com]

mirrors observations for numerous species in the photic zone (Hayden et al. 2014, Kessel et al. 2014). Seasonal movements are typically correlated with environmental factors such as temperature, photoperiod, current strength, and direction (Binder et al. 2011, Hussey et al. 2015), which dictate the tolerance of fish, their prey and/ or predators, and consequently the habitat that they occupy. For Greenland halibut in Cumberland Sound, percent ice cover was a strong predictor of fish occurrence in the northern region during the winter months. In addition, the transition of fish to, and returning from, the northern section of the Sound occurred during ice formation/break up. For the southern region of Cumberland Sound, ice cover was not a strong predictor of fish occurrence, but this may relate to our inability to accurately characterize ice concentrations in that region. During winter months in the central and southern section of the Sound, ice may not be consolidated, with the occurrence of a polynya toward the Sound entrance. Ice chart data cannot discriminate ice concentration at this resolution. Marine mammals, specifically beluga (Delphinapterus leucas) and narwhal (Monodon monoceros) overwinter in the polynya region in the Sound (Kilabuk 1998, DFO 2008) and are known to prey on Greenland halibut (Laidre and Heide-Jorgensen 2005). Decreased predation risk linked with landfast ice formation in the northern region and the seasonal occurrence of marine mammals in the south during the winter, may be a key factor driving the observed seasonal movement of Greenland halibut.

Seasonal movements of Greenland halibut tied with ice cover have also been observed in the inshore fjords of northwestern Greenland (Boje 2002) and Disko Bay (central western Greenland; Boje et al. 2014). The dynamics of the seasonal movement patterns in these regions, however, differ from those observed in our study. In Cumberland Sound, fish move from the southern deep-water region $(>1000 \mathrm{~m})$ northward, either to the same depth or shallower $(\sim 600 \mathrm{~m})$ water with the onset of ice. In Disko Bay, fish displayed the same movement to the inner area of the fjord associated with ice formation but the seasonal depth of occurrence was reversed (summer $300 \mathrm{~m}$ vs. winter $800 \mathrm{~m}$; Boje et al. 2014). In contrast, in northwestern Greenland, whereas fish also moved to the inner section of the fjord, this occurred during the summer ice-free period, although fishing effort may have biased the observed distribution pattern (Boje 2002). Nonetheless, the movement of fish to the inner sections of coastal fjords would seem a consistent migration strategy among these geographically isolated sites, but the timing and environmental conditions at each appear variable.

Boje et al. (2014) reported Greenland halibut occupying colder waters during the winter months in the deep inner icefjord of Disko Bay, a similar trend observed in this and a previous study in Cumberland Sound (Peklova et al. 2012). The negative relationship between presence of fish in the northern region of Cumberland Sound and temperature may suggest a thermal preference. As a result, fish time their movements southward to depart waters that are still cooling despite the diminishing ice as summer approaches and to occupy deeper southern waters where temperatures are higher in order to maintain their thermal 

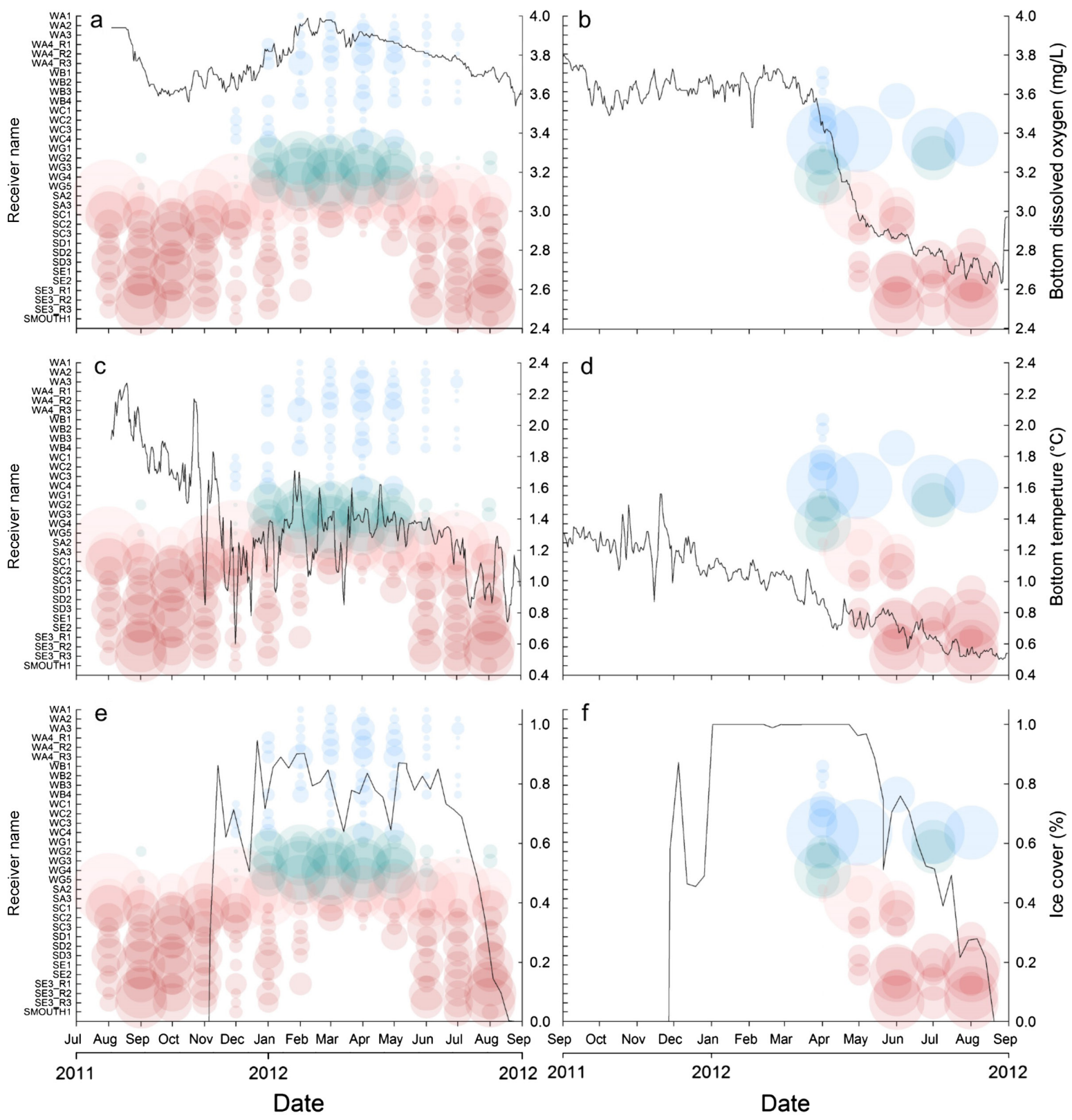

FIG. 7. Environmental variables recorded within Cumberland Sound, with residency index values (RI, see Fig. 5) depicted in the background. The left panels (a, c, and e) are environmental variables recorded in the southern region of Cumberland Sound, including bottom dissolved oxygen and percent ice cover data for the entire deep water southern region (see Appendix S2; both significant factors in the GLMM) and temperature readings from near the mouth of the Sound (SMOUTH, Fig. 1; nonsignificant factor in GLMM). The RI values are for Greenland halibut tagged in the southern region. The right panels (b, d, and f) are bottom dissolved oxygen and percent ice cover for the entire northern region of Cumberland Sound (both significant factors in the GLMM) and temperature recorded in the channel connecting the deep and shallower-water areas of the Sound (Fig. 1; nonsignificant factor) and. The accompanying RI plots are for Greenland halibut tagged in the shallower northern region. [Color figure can be viewed at wileyonlinelibrary.com]

range. Alternatively, movements to colder waters in the northern region may occur to reduce metabolic activity during the ice-cover period when primary productivity is limited (Peklova et al. 2012), but the duration of the residency in the north may be limited by thermal range of Greenland halibut. Equally, GLMM showed that, with decreasing bottom oxygen concentrations, fish moved from the northern region southward. In the southern deep region, fish occupied waters with oxygen concentrations of $\sim 3.6-3.7 \mathrm{mg} / \mathrm{L}$, similar to the values recorded during peak fish occurrence in the northern region. While Greenland halibut and flatfish generally have a low aerobic scope when compared with pelagic fishes (Dupont-Prinet et al. 2013) and are reported to occur in high abundances at low 
TABLE 1. Parameter estimates from generalized linear mixed model predicting Greenland halibut presence in the deep-water southern region of Cumberland Sound relative to fork length and abiotic factors.

\begin{tabular}{lrrrr}
\hline \hline Predictor variables & Value & SE & $t$ & $P$ \\
\hline Intercept & 6.769 & 1.870 & 3.62 & $\mathbf{0 . 0 0 3}$ \\
Fork length & -2.215 & 1.103 & -2.01 & $\mathbf{0 . 0 4 6}$ \\
Wind speed & 0.004 & 0.002 & 1.44 & 0.15 \\
Wind direction & 0.003 & 0.003 & 1.30 & 0.19 \\
Photoperiod & 0.010 & 0.006 & -2.41 & 0.12 \\
Moon illumination & -0.239 & 0.099 & -2.52 & $\mathbf{0 . 0 2}$ \\
Sea ice concentration & -0.004 & 0.002 & 0.56 & $\mathbf{0 . 0 1}$ \\
Sea bottom temperature & 0.078 & 0.140 & -5.04 & 0.58 \\
Sea bottom dissolved oxygen & -2.494 & 0.495 & $<\mathbf{0 . 0 0 1}$
\end{tabular}

Notes: Random effects: halibut ID estimated variance $=0.77 \pm 0.88$; tagging location estimated variance $=0.00002 \pm 0.004$ (both are mean $\pm \mathrm{SE}$ ). Boldface type highlights $P<0.05$.

TABLE 2. Parameter estimates from generalized linear mixed model predicting Greenland halibut presence in the shallow northern region of Cumberland Sound relative to fork length and abiotic factors.

\begin{tabular}{|c|c|c|c|c|}
\hline Predictor variables & Value & SE & $t$ & $P$ \\
\hline Intercept & -11.830 & 2.738 & -4.32 & $<0.001$ \\
\hline Fork length & 1.761 & 1.967 & 0.89 & 0.37 \\
\hline Wind speed & 0.005 & 0.004 & 1.46 & 0.15 \\
\hline Wind direction & -0.005 & 0.004 & -1.21 & 0.22 \\
\hline Photoperiod & 0.065 & 0.035 & 1.88 & 0.06 \\
\hline Moon illumination & 0.015 & 0.182 & 0.08 & 0.93 \\
\hline Sea ice concentration & 0.042 & 0.004 & 9.57 & $<0.001$ \\
\hline Sea bottom temperature & -3.619 & 0.776 & -4.66 & $<0.001$ \\
\hline Sea bottom dissolved oxygen & 1.682 & 0.580 & 2.90 & 0.003 \\
\hline
\end{tabular}

Notes: Random effects: halibut ID estimated variance $=0.78 \pm 0.88$; tagging location estimated variance $=0.36 \pm 0.60$ (both are mean $\pm \mathrm{SE}$ ). Boldface type highlights $P<0.05$.

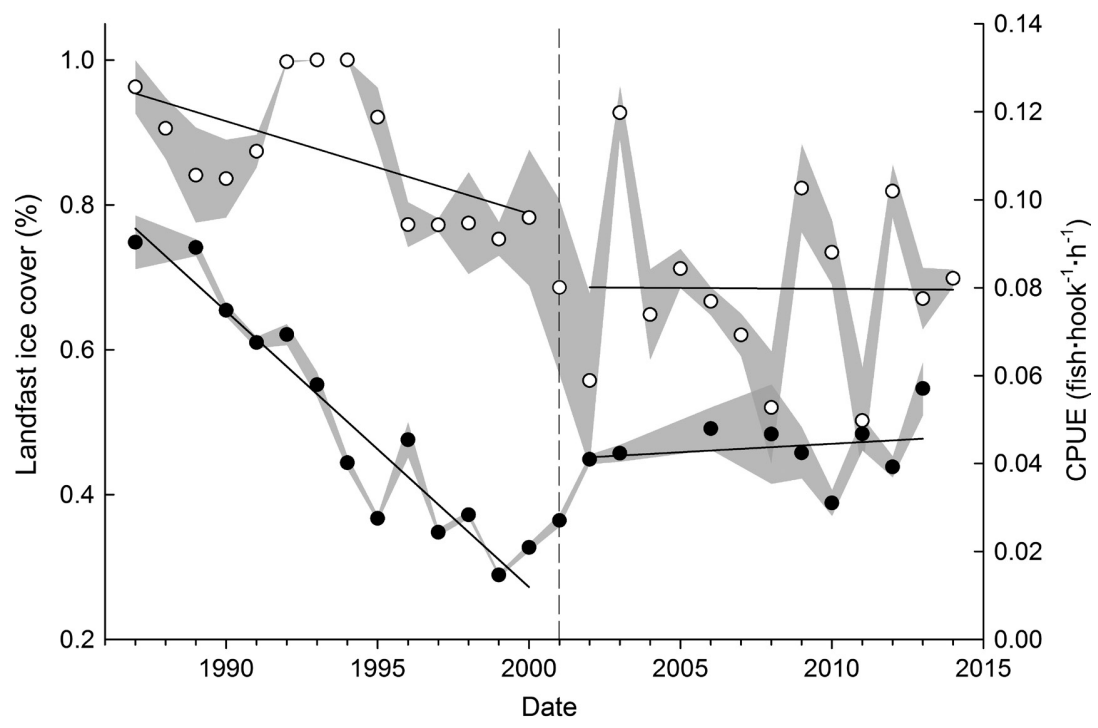

FIG. 8. Piecewise regression of percent landfast ice cover (open circles) for the area north of the Cumberland Sound Management Boundary (CSMB) and catch per unit effort (CPUE, filled circles) of the community-based winter fishery that takes place in the same region. Landfast ice was used as a measure of accessibility of fishers to the fishing grounds. Significant declines in both landfast ice and CPUE were found (landfast ice, $R^{2}=0.325, y=-0.013 x+26.314, P=0.03$; CPUE, $R^{2}=0.917, y=-0.006+12.562$, $P<0.0001$ ) up until a break point at the year 2001 (indicated by the vertical dashed line), after which no significant relationship exists for either variable (landfast ice, $R^{2}=0.0007, P>0.05$; CPUE, $R^{2}=0.044, P>0.05$ ). The gray shading represents \pm SE for each year for each variable. 


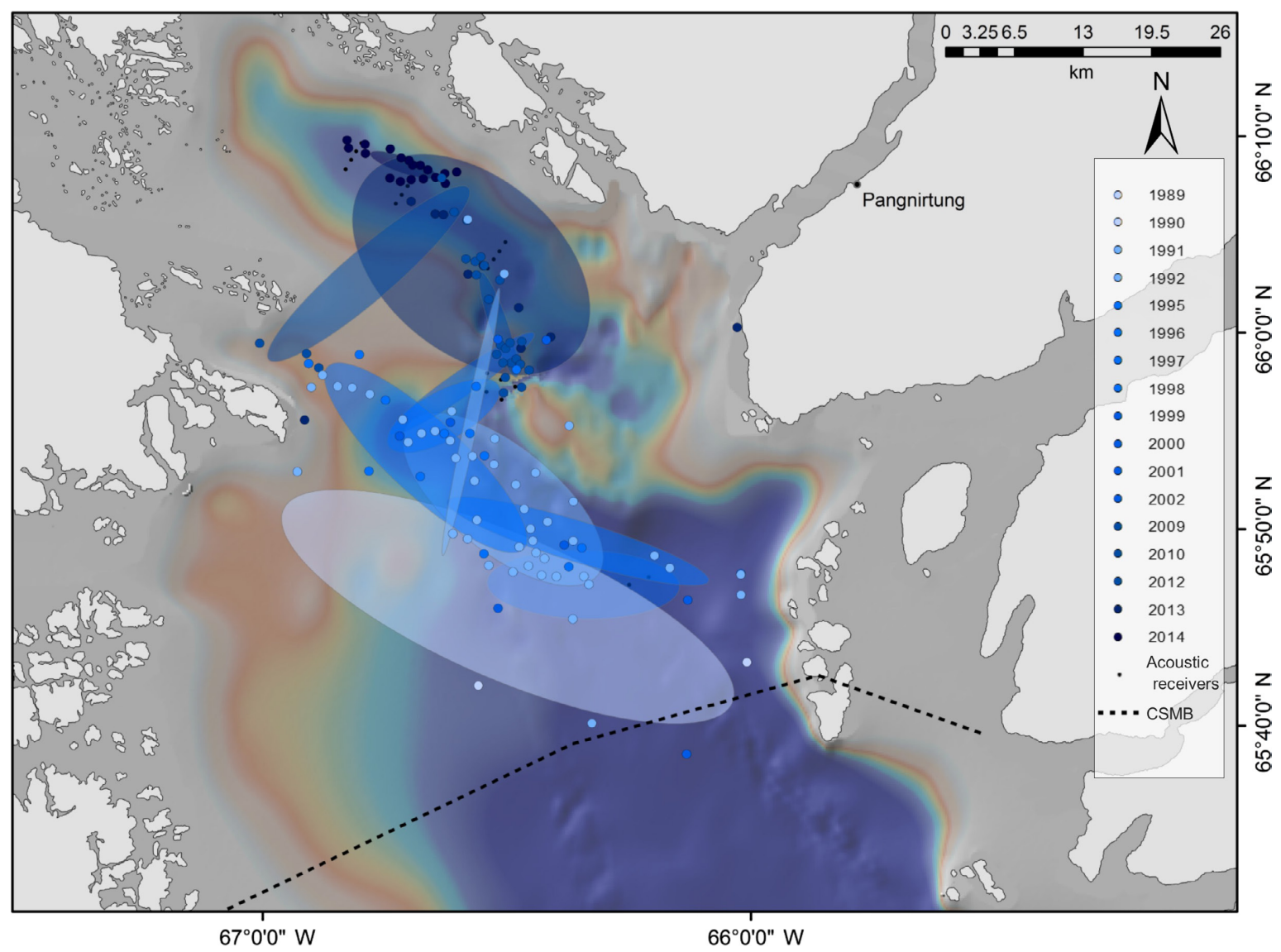

FIG. 9. Map showing fishers' locations in Cumberland Sound over the lifespan of the fishery (1987-2013). Bivariate ellipses encompass the core $40 \%$ of the fishing areas used within a given year, with individual locations of fishers marked by dots. Colors of ellipses and dots are graduated from the lightest blue in the first year to darker colors in more recent years. Small black circles are acoustic receiver locations from the present study. Note that, for some years, ellipses were not calculated either because no data were reported by fishermen or because sample size was too small. [Color figure can be viewed at wileyonlinelibrary.com]

dissolved oxygen concentrations (Youcef et al. 2013), it is possible that dissolved oxygen concentration regulates the occurrence of these fish, through sensitivity to changes such as were previously documented for spotted ratfish (Hydrolagus colliei) and petrale sole (Eopsetta jordani; Keller et al. 2015). Overall, these data suggest that a combination of biotic and abiotic factors drive these seasonal movements including potential thermal and oxygen-saturation regimes, predator avoidance or prey availability (Boje 2002, Hovde et al. 2002).

For deep-water fish species, data on horizontal movement patterns have been particularly complex to collect. Typically, standard tag-recapture programs only provide the tag and recapture location with no detail on specific movement patterns between those two time points. More recently, archival data loggers that collect highresolution depth and temperature time series data were attached to Greenland halibut off West Greenland (Boje et al. 2014). These tags, which must be physically recovered to access the data, provided detailed information on the thermal and vertical preferences of Greenland halibut over time, but data return rate was low (data were retrieved from 10 of 181 tagged fish). In addition, these tags do not provide any horizontal movement data aside from the release and recapture locations. Similarly, satellite telemetry of Greenland halibut recorded high-resolution depth and temperature profiles for individual fish and provided the first evidence of seasonal movement within Cumberland Sound (Peklova et al. 2012). Although most of the deployed satellite tags transmitted data (eight of nine), the tags are expensive and cannot provide any horizontal location data at these deep depths because no light data are available for geolocation.

The known benefits of acoustic telemetry for monitoring fish in the epipelagic zone (Hussey et al. 2015) were expected to apply to monitoring deep-water species. Specifically, tags with long battery life (up to $10 \mathrm{yr}$ ) and of various sizes (can equip fish weighing as little as $\sim 10 \mathrm{~g}$ ) can be implanted in fish, enabling long-term monitoring of individuals. Following this approach, Weng (2013) successfully monitored the movements of three bottom-fish species, (scarlet snapper; Etelis coruscans; red snapper; Etelis carbunculus and pink snapper; Pristipomoides filamentosus) at depths of 100-400 m 
for up to $40 \mathrm{~d}$ in Hawaii, while the deep sea shark, Centrophorous zeehaani, was monitored at depths of 300-700 m over an average of $408 \mathrm{~d}$ off Southern Australia (Daley et al. 2015). Acoustic telemetry studies, through the deployment of fixed receivers, provide the only viable option to passively track horizontal movements of these deep-water species. Long-battery-life receivers are now available (for example VEMCO VR4W) that can be deployed for 6 yr (rather than one) with data downloaded on a regular basis via hydroacoustic link (rather than physical retrieval). This reduces the costs of monitor deployment and maintenance on an annual basis and minimizes disturbance to the environment. At present, these monitors can only operate at depths $<500 \mathrm{~m}$, but given interest in commercial exploitation of deep-water fish and the requirement for movement data, it is anticipated that monitors will be developed for use in waters $>500 \mathrm{~m}$.

\section{The role of telemetry data in Arctic fisheries management}

Acoustic telemetry revealed that Greenland halibut tagged in Cumberland Sound crossed the CSMB, with most fish inhabiting the southern deep-water section during the open-water summer period and the region north of the management line encompassing the northern end of the deep-water channel, the gate, and the shallower northern basin, during the ice-covered winter period. Although individual variability in movement was observed, including a few fish detected either in the northern or southern region year round, RI values clearly showed a seasonally shifting distribution of the sampled population. These data identify that the majority of Greenland halibut are not resident in the Cumberland Sound winter fishing grounds as was previously assumed (Treble 2003). Consequently, a summer fishery in the southern deep-water region of Cumberland Sound south of the CSMB would target the same fish as the winter fishery. Given that the declaration of the CSMB was based on resident fish, i.e., a sink population that is considered discrete from the offshore population, a TAC solely assigned to the fishing region north of the CSMB would seem inappropriate. Moreover, when considering the development of a southern open-water fishery in Division $0 \mathrm{~B}$ south of the CSMB using large offshore vessels that are able to fish intensively, these movement data raise concern over the long-term sustainability of the community based winter fishery. As a result, following consideration of these telemetry data by the Nunavut Wildlife Management Board, the Government of Nunavut and the Department of Fisheries and Oceans, the CSMB was conditionally moved to the entrance of Cumberland Sound in 2014. It was further requested that the community support continued telemetry monitoring within the Sound to determine if the seasonal movement of fish is replicated across years. In 2014, acoustic equipment was redeployed in Cumberland Sound following consultation with the community for a further two years of data collection.

Since the inception of the community winter fishery, deteriorating ice conditions (ice extent, thickness, and stability) have occurred within Cumberland Sound, driving accessible areas northward and confining the fishing grounds to predominantly shallower water regions outside of the previously preferred sites. During the early years of the fishery, fishers targeted locations at the northern end of the southern deep-water region where catch rates were highest (Receivers SA2 and SA3; DFO 2008; Dennard et al. 2010). In 1996 a severe storm caused the edge of the landfast ice to break up, which led to significant loss of fishing gear on the ice and for the next 5 yrs the number of fishers dropped considerably. During that same period, fisher locations moved consecutively northward as a result of poorer landfast ice (Dennard et al. 2010; these data). From 2002, increased effort and a longer fishing season led to higher catches and more recently, based on these telemetry data, fishers located a deep-water productive area in 2013 in the northern region that led to improved CPUE and a renewed interest in the fishery. These telemetry data, however, suggest that the originally favored deep-water winter fishing grounds at the northern end of the deep-water channel (region of SA monitors) are still where most fish are resident during the winter period. Few tagged fish moved into the very northern regions. This suggests that poorer quality ice may limit the winter community fishery from accessing the most productive fishing grounds, but further telemetry monitoring and survey work is required in the northern deeper water pockets to determine to what extent fish move toward this area of the Sound.

Predicted reductions in Arctic sea ice extent (Stroeve et al. 2007) could mean that the community winter fishery as it stands will not exist in the future. With the critical need for economic growth through job opportunities in Arctic Inuit communities, coupled with the large investments that have been made in developing this fishery through establishing a fish processing plant and subsidizing fishing equipment, the only viable option for the community fishery as currently equipped may be as a summer, open-water fishery. In 2014, community members for the first time successfully fished from a larger vessel $(\sim 12.2 \mathrm{~m})$ during the open water summer period (P. Kilabuk, personal communication), noting most vessels operated in Canadian Arctic communities are $\sim 5.5 \mathrm{~m}$ long and too small to fish deep-water longlines. Future development of the fishery will rely on the growth of an open-water summer fishery using larger communityoperated vessels to complement the ongoing winter ice fishery, similar to the Greenland fishery model (GN 2010). If this were to occur, over time, the fishery would likely transition to an open-water fishery with a longer fishing season as ice extent continues to decline. When considering long-term fisheries planning, the movement of the CSMB to the entrance of the Sound allows the community fishery to exploit the TAC across both winter 
and summer fishing areas and addresses the long-term climate scenario. This is based on the assumption, however, that the loss of ice will not impact the overall food-web structure to such an extent as to modify the occurrence and abundance of Greenland halibut in the Sound (Morgan et al. 2013). Research is required to better predict the impact of sea-ice loss on deep-water ecosystems, especially when considering commercially important species whose populations will likely be placed under increasing pressure as the Arctic region becomes more accessible to fisheries (Steiner et al. 2015). Equally, there is a necessity for carefully considered long-term monitoring programs for these data limited stocks to ensure sustainable harvests.

\section{Telemetry and its future application to Arctic Fisheries}

While these acoustic-telemetry data clearly indicate that Greenland halibut were not resident within the winter fishing grounds in Cumberland Sound year round and the relocated CSMB accounts for the observed seasonal movements of fish, it is now imperative to investigate the connectivity between inshore and offshore Greenland halibut populations. These inshore populations of Greenland halibut have been considered to constitute "sink populations" whereby animals reach a certain size, enter inshore waters and then remain in these environments. The term "sink" arises from the fact that the fish are thought to remain in the system and there is little or no evidence of spawning occurring (Simonsen and Gundersen 2005), basically implying a dead end. To date, six acoustically tagged Greenland halibut ranging in size from 60 to $76 \mathrm{~cm}$ fork length $(66.6 \pm 5.6 \mathrm{~cm}$ [mean $\pm \mathrm{SD}])$ have been detected at the entrance to the Sound and one has been caught in offshore waters. Similarly, previous tag-recapture data documented connectivity between the mouth of Cumberland Sound and the offshore, albeit through a small number of recaptures (Treble 2003). These data now question the "sink" hypothesis, raising questions over the levels of mixing of this population with other geographical populations and its contribution to overall recruitment and genetic diversity. Quantifying connectivity between Cumberland Sound and Baffin Bay and Davis Strait is extremely important for fisheries management since changes in the offshore fishery could have implications for the Cumberland Sound fishery, depending on the degree of connectivity. The deployment of a line of consecutive acoustic receivers across the deep water channel at the entrance to Cumberland Sound, spaced at intervals to maximize detection efficiency to approximately $100 \%$, would make it possible to quantify immigration/emigration of tagged fish into/out of Cumberland Sound and allow managers to estimate how changes in either fishery will affect the other. This concept follows the gate array designs used to monitor river migrations (Welch et al. 2009), and would provide a method to quantify the level of subpopulation connectivity in species with diffuse movement patterns, but whose movements are constrained in specific areas, such as deep water channels.

This study demonstrates the power of acoustic telemetry for improving our understanding of species ecology and our ability to effectively manage exploited populations. Ongoing technological improvements will only increase the opportunities for data collection and improve our understanding of frontier ecosystems.

\section{ACKNOWLEDGMENTS}

We are indebted to the community of Pangnirtung, especially the local fishers and the Hunters and Trappers Organization for assistance with all aspects of this program. We thank Devon Imrie, Kendra Ulrich, Jeremiah Young, and Angela Young for logistical support for field operations. The crew of the Nuliajuk and the Stellie II were critical in supporting all field activities. Funding for this study was provided by the Natural Sciences and Engineering Research Council of Canada (NSERC) and Canadian Foundation for Innovation (CFI) via the Ocean Tracking Network and a Canadian Research Chair to A. T. Fisk. N. E. Hussey, K. J. Hedges, S. H. Ferguson, and A. T. Fisk were funded by the Government of Nunavut. All telemetry equipment and associated moorings were provided by the Ocean Tracking Network.

\section{Literature Cited}

Afonso, P., G. Graca, G. Berke, and J. Fontes. 2012. First observations on seamount habitat use of blackspot seabream (Pagellus bogaraveo) using acoustic telemetry. Journal of Experimental Marine Biology and Ecology 436:1-10.

Albert, O. T., and T. Vollen. 2015. A major nursery area around Svalbard archipelago provides recruits for the stocks in both Greenland halibut management areas in the Northeast Atlantic. ICES Journal of Marine Science. https://doi.org/ 10.1093/icesjms/fsu191

Bedard, J. M., S. Vagle, J. M. Klymak, W. J. Williams, B. Curry, and C. M. Lee. 2015. Outside influences on the water column of Cumberland Sound, Baffin Island. Journal of Geophysical Research 120:5000-5018.

Binder, T. R., S. J. Cooke, and S. G. Hinch. 2011. The biology of fish migration. Pages 1921-1927 in A. P. Farrell, editor. Encyclopedia of fish physiology: from genome to environment. Volume 3. Academic Press, San Diego, California, USA.

Boje, J. 2002. Intermingling and seasonal migrations of Greenland halibut (Reinhardtius hippoglossoides) populations determined from tagging studies. Fisheries Bulletin 100:414 422.

Boje, J., S. Neuenfeldt, C. R. Sparrevohn, O. Eigaard, and J. W. Behrens. 2014. Seasonal migration, vertical activity and winter temperatures experience of Greenland halibut Reinhardtius hippoglossoides in West Greenland waters. Marine Ecology Progress Series 508:211-222.

Bond, M. E., E. A. Babcock, E. K. Pikitch, D. L. Abercrombie, N. F. Lamb, and D. D. Chapman. 2012. Reef sharks exhibit site-fidelity and higher relative abundance in marine reserves on the Mesoamerican Barrier Reef. PLoS ONE 7:e32983.

Bowering, W. R., and W. B. Brodie. 1995. Greenland halibut (Reinhardtius hippoglossoides). A review of the dynamics of its distribution and fisheries off eastern Canada and Greenland. Pages 113-160 in A. G. Hopper, editor. NATO ASI series: deep-water fisheries of the North Atlantic Oceanic slope. Kluwer Academic Publishers, Dordrecht, The Netherlands.

Bowering, W. R., and A. K. Chumakov. 1989. Distribution and relative abundance of Greenland halibut (Reinhardtius hippoglossoides (Walbaum)) in the Canadian Northwest Atlantic 
from the Davis Strait to the Northern Grand Bank. Fisheries Research 7:301-327.

Christiansen, J. S., C. W. Mecklenburg, and O. V. Karamushko. 2014. Arctic marine fishes and their fisheries in light of global change. Global Change Biology 20:352-359.

Clark, M. 2001. Are deepwater fisheries sustainable? The example of orange roughy (Hoplostethus atlanticus) in New Zealand. Fisheries Research 51:123-135.

Clark, M. R., O. F. Anderson, R. I. C. C. Francis, and D. M. Tracey. 2000. The effects of commercial exploitation on orange roughy (Holostethus atlanticus) from the continental slope of the Chatham Rise, New Zealand, from 1979 to 1997. Fisheries Research 45:217-238.

Crawley, M. J. 2007. The R book. Wiley, New York, New York, USA.

Daley, R. K., A. Williams, M. Green, B. Barker, and P. Brodie. 2015. Can marine reserves conserve vulnerable sharks in the deep sea? A case study of Centrophorus zeehaani (Centrophoridae), examined with acoustic telemetry. Deep Sea Research Part II 115:127-136.

Dennard, S. T., M. A. MacNeil, M. A. Treble, S. Campana, and A. T. Fisk. 2010. Heirarchical analysis of a remote Arctic artisanal longline fishery. ICES Journal of Marine Science 67:41-51.

DFO (Department of Fisheries and Oceans). 2008. Fixed gear recommendations for the Cumberland Sound Greenland halibut fishery. DFO Canadian Science Advisory Secretariat Science Report 2008/11. Fisheries and Oceans Canada, Winnipeg, Manitoba, Canada.

Dupont-Prinet, A., M. Vagner, D. Chabot, and C. Audet. 2013. Impacts of hypoxia on the metabolism of Greenland halibut (Reinhardtius hippoglossoides). Canadian Journal of Fisheries and Aquatic Sciences 70:461-469.

Espinoza, M., E. J. J. Ledee, C. A. Simpfendorfer, A. J. Tobin, and M. R. Heupek. 2015. Contrasting movements and connectivity of reef associated sharks using acoustic telemetry: implications for management. Ecological Applications 25:2101-2118.

Francis, R. I. C. C., M. R. Clark, R. P. Coburn, K. D. Field, and P. J. Grimes. 1995. Assessment of the ORH 3B orange roughy fishery for the 1994-1995 fishing year. NZ Fisheries Assessment Research Document 95/4. NIWA, Wellington, New Zealand.

GN (Government of Nunavut). 2010. Greenland technology transfer. Fisheries and Sealing Division, Department of Environment, Government of Nunavut, Iqaluit, Nunavut, Canada.

Gregg, J. L., D. M. Anderl, and D. K. Kimura. 2006. Improving the precision of otolith-based age estimates for Greenland halibut (Reinhardtius hippoglossoides) with preparation methods adapted for fragile sagittae. Fisheries Bulletin 104: 643-648.

Hayden, T. A., C. M. Holbrook, D. G. Fielder, C. S. Vandergoot, R. A. Bergstedt, J. M. Cettmers, C. C. Krueger, and S. J. Cooke. 2014. Acoustic telemetry reveals large-scale migration patterns of walleye in Lake Huron. PLoS ONE 9: e114833.

Heupel, M. R., J. M. Semmens, and A. J. Hobday. 2006. Automated acoustic tracking of aquatic animals: scales, design and deployment of listening station arrays. Marine and Freshwater Research 57:1-13.

Hovde, S. C., O. T. Albert, and E. M. Nilssen. 2002. Spatial, seasonal and ontogenetic variation in diet of Northeast Arctic Greenland halibut (Reinhardtius hippoglossoides). ICES Journal of Marine Science 59:421-437.

Hussey, N. E. 2016. Raw detection data for movements of a deep-water flatfish: establishing marine fisheries management boundaries in coastal Arctic fisheries. https://doi.org/10. 14286/2016_hussey_greenland_ecoapp

Hussey, N. E., et al. 2015. Aquatic animal telemetry: a panoramic window into the underwater world. Science 348:1255642.

Jackson, A. L., R. Inger, A. C. Parnell, and S. Bearhop. 2011. Comparing isotopic niche widths among and within communities: SIBER - Stable Isotope Bayesian Ellipses in R. Journal of Animal Ecology 80:595-602.

Jørgensen, O. A., and N. Hammeken Arboe. 2013. Distribution of the commercial fishery for Greenland halibut and Northern shrimp in Baffin Bay. Technical Report No. 91. Greenland Institute of Natural Resources, Pinngortitaleriffik, Greenland. Jørgensen, O. A., and M. A. Treble. 2015. Assessment of the Greenland Halibut Stock Component in NAFO Subarea $0+$ Division 1A Offshore + Divisions 1B-1F. NAFO SCR Document 15/32. Northwest Atlantic Fisheries Organization, Nova Scotia, Canada, $57 \mathrm{pp}$.

Keller, A. A., L. Ciannelli, W. W. Wakefield, V. Simon, J. A. Barth, and S. D. Pierce. 2015. Occurrence of demersal fishes in relation to near-bottom oxygen levels within the California Current large marine ecosystem. Fisheries Oceanography 24:162-176.

Kessel, S. T., D. D. Chapman, B. R. Franks, T. Gedamke, S. H. Gruber, J. M. Newman, E. R. White, and R. G. Perkins. 2014. Predictable temperature-regulated residency, movement and migration in a large highly mobile marine predator (Negaprion brevirostris). Marine Ecology Progress Series 514: 175-190.

Kilabuk, P. 1998. A study of Inuit knowledge of the Southeast Baffin beluga. Nunavut Wildlife Management Board, Iqaluit, Nunavut, Canada.

Laidre, K. L., and M. P. Heide-Jorgensen. 2005. Winter feeding intensity of narwhals (Monodon monoceros). Marine Mammal Science 21:45-57.

Lédée, E. J., M. R. Heupel, A. J. Tobin, and C. A. Simpfendorfer. 2015. Movements and space use of giant trevally in coral reef habitats and the importance of environmental drivers. Animal Biotelemetry 3:6.

MacNeil, M. A., N. A. J. Graham, J. E. Cinner, N. K. Dulvy, P. A. Loring, S. Jennings, N. V. C. Polunin, A. T. Fisk, and T. R. McClanahan. 2010. Transitional states in marine fisheries: adapting to predicted global change. Philosophical Transactions of the Royal Society B 365:3753-3763.

Morgan, M. J., D. Garabana, R. M. Rideout, E. Roman, A. Perez-Rodrigues, and F. Sborido-Rey. 2013. Changes in distribution of Greenland halibut in a varying environment. ICES Journal of Marine Science 70:352-361.

Nakagawa, S., and H. Schielzeth. 2013. A general and simple model for obtaining $R^{2}$ from generalized liner mixed effects models. Methods in Ecology and Evolution 4:133-142.

Norse, E. A., et al. 2012. Sustainability of deep-sea fisheries. Marine Policy 36:307-320.

Nygaard, R., and J. Boje. 2013. Updated indices for the Greenland Halibut Stock Component in NAFO Division 1A Inshore. NAFO SCR Document 13/48. Northwest Atlantic Fisheries Organization, Nova Scotia, Canada.

Peklova, I., N. E. Hussey, K. J. Hedges, M. A. Treble, and A. T. Fisk. 2012. Depth and temperature preferences of the deepwater flatfish Greenland halibut Reinhardtius hippoglossoides in an Arctic marine ecosystem. Marine Ecology Progress Series 467:193-205.

Pike, D. G. 1994. The fishery for Greenland halibut (Reinhardtius hippoglossoides) in Cumberland Sound, Baffin Island, 19871992. Canadian Technical Report of Fisheries and Aquatic Sciences, Government of Canada Publications, 25pp.

Priede, I. G., and P. M. Bagley. 2000. In situ studies on deepsea demersal fishes using autonomous unmanned lander 
platforms. Oceanography and Marine Biology: An Annual Review 38:357-392.

R Development Core Team. 2014. R: a language and environment for statistical computing. R Foundation for Statistical Computing, Vienna, Austria. https://www.r-project.org

Raby, G. D., S. G. Hinch, D. A. Patterson, J. A. Hills, L. A Thompson, and S. J. Cooke. 2015. Mechanisms to explain purse seine bycatch mortality of coho salmon. Ecological Applications 25:1757-1775.

Scott, W. B., and M. G. Scott. 1988. Atlantic fishes of Canada. Canadian Bulletin of Fisheries and Aquatic Sciences 219:731 pp.

Simonsen, C. S., and A. C. Gundersen. 2005. Ovary development in Greenland halibut Reinhardtius hippoglossoides in west Greenland waters. Journal of Fish Biology 67: 1299-1317.

Simpfendorfer, C. A., C. Huveneers, A. Steckenreuter, K. Tattersall, X. Hoenner, R. Harcourt, and M. R. Heupel. 2015. Ghosts in the data: false detections in VEMCO pulse position modulating acoustic telemetry monitoring equipment. Animal Biotelemetry 3:55.

Sissenwine, M. P., and P. M. Mace. 2007. Can deep water fisheries be managed sustainably? in FAO expert consultation on deep-sea fisheries of the high seas, Bangkok, Thailand, 21-23 November 2006. Fisheries Report No. 838. FAO, Rome, Italy.

Steiner, N., et al. 2015. Observed trends and climate projections affecting marine ecosystems in the Canadian Arctic. Environmental Reviews 23:191-239.

Stroeve, J., M. M. Holland, W. Meier, T. Scambos, and M. Serreze. 2007. Arctic sea ice decline: faster than forecast. Geophysical Research Letters 34:1-5.

Treble, M. A. 2003. Results of a Greenland halibut (Reinhardtius hippoglossoides) tagging project in Cumberland Sound, NAFO Division 0B, 1997-2000. NAFO SCR Document 03/41. Northwest Atlantic Fisheries Organization, Nova Scotia, Canada.
Treble, M. A., and O. A. Jorgensen. 2002. Summary of results for Greenland halibut from trawl surveys conducted in NAFO Subareas 0 and 1 from $61^{\circ} \mathrm{N}$ to $74^{\circ} \mathrm{N}$ in 2001. NAFO SCR Document 02/60. Northwest Atlantic Fisheries Organization, Nova Scotia, Canada, 8 pp.

Treble, M. A., S. E. Campana, R. J. Wastle, C. M. Jones, and J. Boje. 2008. Growth analysis and age validation of a deepwater Arctic fish, the Greenland halibut (Reinhardtius hippoglossoides). Canadian Journal of Fisheries and Aquatic Sciences 65:1047-1059.

Welch, D. W., M. C. Melnychuk, E. R. Rechisky, A. D. Porter, M. C. Jacobs, A. Ladouceur, R. S. McKinley, and G. D. Jackson. 2009. Freshwater and marine migration and survival of endangered Cultus Lake sockeye salmon (Oncorhynchus nerka) smolts using POST, a large scale acoustic telemetry array. Canadian Journal of Fisheries and Aquatic Sciences 66:736-750.

Welch, D. W., A. D. Porter, and P. Winchell. 2014. Migration behavior of maturing sockeye (Oncorhynchus nerka) and Chinook salmon (O. tshawytscha) in Cook Inlet, Alaska and implications for management. Animal Biotelemetry 2:35.

Weng, K. C. 2013. A pilot study of deepwater fish movement with respect to marine reserves. Animal Biotelemetry 1:17.

White, E., M. Mihoff, B. Jones, L. Bajona, and E. Halfyard. 2014. White-Mihoff false filtering tool. http://members. oceantrack.org/data/otn-tool-box

Wilson, G. D. F., and R. R. Hessler. 1987. Speciation in the deep sea. Annual Review of Ecology, Evolution and Systematics 18:185-207.

Youcef, W. A., Y. Lambert, and C. Audet. 2013. Spatial distribution of Greenland halibut Reinhardtius hippoglossoides in relation to abundance and hypoxia in the estuary and Gulf of St. Lawrence. Fisheries and Oceanography 22:41-60.

Young, A. 2010. Development of the Cumberland Sound inshore summer fishery 2009. Fisheries and Sealing Division, Department of Environment, Government of Nunavut, Iqaluit, Nunavut, Canada.

\section{SUPPORTING INFORMATION}

Additional supporting information may be found in the online version of this article at http://onlinelibrary.wiley.com/ doi/10.1002/eap.1485/full 